IZA DP No. 6418

Does Uninsurance Affect the Health Outcomes of the Insured? Evidence from Heart Attack Patients in California

N. Meltem Daysal

March 2012 


\title{
Does Uninsurance Affect the Health Outcomes of the Insured? Evidence from Heart Attack Patients in California
}

\author{
N. Meltem Daysal \\ Tilburg University \\ and IZA \\ Discussion Paper No. 6418 \\ March 2012 \\ IZA \\ P.O. Box 7240 \\ 53072 Bonn \\ Germany \\ Phone: +49-228-3894-0 \\ Fax: +49-228-3894-180 \\ E-mail: iza@iza.org
}

\begin{abstract}
Any opinions expressed here are those of the author(s) and not those of IZA. Research published in this series may include views on policy, but the institute itself takes no institutional policy positions.

The Institute for the Study of Labor (IZA) in Bonn is a local and virtual international research center and a place of communication between science, politics and business. IZA is an independent nonprofit organization supported by Deutsche Post Foundation. The center is associated with the University of Bonn and offers a stimulating research environment through its international network, workshops and conferences, data service, project support, research visits and doctoral program. IZA engages in (i) original and internationally competitive research in all fields of labor economics, (ii) development of policy concepts, and (iii) dissemination of research results and concepts to the interested public.
\end{abstract}

IZA Discussion Papers often represent preliminary work and are circulated to encourage discussion. Citation of such a paper should account for its provisional character. A revised version may be available directly from the author. 


\section{ABSTRACT}

\section{Does Uninsurance Affect the Health Outcomes of the Insured? Evidence from Heart Attack Patients in California ${ }^{*}$}

In this paper, I examine the impact of uninsured patients on the health of the insured, focusing on one health outcome - the in-hospital mortality rate of insured heart attack patients. I employ panel data models using patient discharge and hospital financial data from California (1999-2006). My results indicate that uninsured patients have an economically significant effect that increases the mortality rate of insured heart attack patients. I show that these results are not driven by alternative explanations, including reverse causality, patient composition effects, sample selection or unobserved trends and that they are robust to a host of specification checks. My results also indicate that the primary channel for the observed spillover effects is increased hospital uncompensated care costs. Although data limitations constrain my capacity to check how hospitals change their provision of care to insured heart attack patients in response to reduced revenues, the evidence I have suggests a modest increase in the quantity of cardiac services without a corresponding increase in hospital staff.

JEL Classification: $\quad I 10, I 11, I 18$

Keywords: $\quad$ uninsurance, spillovers, heart attack mortality, hospitals

Corresponding author:

N. Meltem Daysal

Tilburg University

Warandelaan 2

P.O. Box 90153

5000 LE Tilburg

The Netherlands

E-mail: meltem.daysal@uvt.nl

\footnotetext{
* I am particularly indebted to Judith Hellerstein and Mark Duggan for their guidance and support throughout this project. I am also grateful for useful comments provided by Michael Anderson, Aimee Chin, Bill Evans, Darrell Gaskin, Serkan Ozbeklik, Willard Manning, Martin Salm, Kosali Simon, Jon Skinner, Neeraj Sood, Mircea Trandafir and seminar participants at Aarhus University, Congressional Budget Office, Johns Hopkins, Mathematica Health Systems Change, RAND, Sabanci University, Tilburg University, Tinbergen Institute, University of Maryland, W.E. Upjohn Institute for Employment Research, 2010 Biennial Conference of American Society of Health Economists, 2010 European Society for Population Economics Meetings, 2009 Population Association of America Annual Meetings, 2008 Southern Economic Association Meetings. I thank the Department of Economics at the University of Maryland and the Maryland Population Research Center for financial support in obtaining the data and the California Office of Statewide Health Planning and Development for making the data available and for attending my queries while performing this study. All remaining errors are my own.
} 


\section{Introduction}

During the past few decades, the United States health care market has experienced dramatic changes. One feature of the health care market that has stayed constant is the persistently large number of Americans who lack health insurance coverage. Consequently, the problem of the uninsured has had a long-standing center stage place in public policy debates.

While there is an extensive body of research on how lack of insurance affects an individual's own health outcomes, health care utilization and economic well-being, there is very little evidence on how the uninsured affect the provision of care to insured patients. ${ }^{1}$ The literature on the community effects of uninsurance has almost exclusively focused on how the uninsured affect insured individuals' access to health care (Gaskin and Needleman, 2003; Needleman and Gaskin, 2003; Pagán and Pauly, 2006; Sabik, forthcoming), and the handful of papers studying effects on quality of care relied on self-reported measures (Pauly and Pagán, 2007; Pagán et al., 2007; Pauly and Pagán, 2009). In this paper, I investigate the community effects of uninsurance by examining its impact on an outcome-of-care quality measure. In particular, I examine the effects of uninsured discharges on the health outcomes of insured heart attack patients (Acute Myocardial Infarction, AMI) using patient discharge and hospital financial data from California hospitals (1999-2006) merged with spatial geocode information.

California is an appropriate setting to study this question for several reasons. It is the most populous state in the United States, accounting for 12 percent of the total population in 2000. It is also a high uninsurance state: between 2004 and 2006, over 20 percent of its residents were uninsured compared to a national uninsurance rate of 17 percent. Because

\footnotetext{
${ }^{1}$ For a review of the literature examining the effects of insurance coverage on an individual's own outcomes, see Institute of Medicine (2002, 2009).
} 
of its size, it has the largest number of uninsured, close to 7 million during $2004-2006 .^{2}$ In addition, it is a state where uninsurance was identified as a major policy issue: even before the enactment of the national health care reform, policy makers in California made deliberate attempts to bring the state to universal coverage (Curtis and Neuschler, 2009). Finally, the datasets collected by the Office of Statewide Health Planning and Development are among the richest U.S. health care datasets available to researchers: the patient discharge data provides very detailed clinical information on every discharge from non-federal hospitals, and the hospital financial data includes detailed balance sheet information allowing for an exploration of the mechanisms through which the uninsured might impact insured health outcomes.

I focus my attention on heart attack patients for a number of reasons. First of all, it is an important health outcome, representing a common cause of death for both men and women in the United States. It is also a health event for which the cost of treatment has increased substantially over time. Second, it is a health condition for which evidence suggests that high in-hospital mortality may be associated with insufficient quality of care. Finally and most importantly, focusing on heart attack patients ameliorates a potential bias arising from the endogenous choice of hospitals by patients and of location by hospitals.

Lack of insurance and AMI mortality seem to be related in the raw data. From 1999 to 2006, the fraction of uninsured discharges in Los Angeles and San Francisco fell from roughly $6.4 \%$ to $5.8 \%$ and from $7 \%$ to $5.5 \%$, respectively, while uninsured discharges in Sacramento increased from approximately $3.5 \%$ to over 5\%. During that same time period, Los Angeles and San Francisco counties experienced 26-30\% declines in their insured AMI mortality rates, against the backdrop of a statewide reduction of roughly 19\%. The drop in insured heart

\footnotetext{
${ }^{2}$ All the statistics are provided by California Healthcare Foundation (2007).
} 
attack mortality in Sacramento, on the other hand, was much slower (13\%) when compared to the overall statewide downward trend. In the empirical analysis, I employ panel data models to test whether the observed difference in insured AMI mortality trends is caused by differences in the trends of market uninsurance rates. My baseline empirical specification estimates the impact of the fraction of uninsured patients in a hospital's health care market ${ }^{3}$ on the mortality rate of its insured heart attack patients, controlling for hospital and year effects. My preferred measure of uninsurance is calculated at the health care market level because the choice of a health care market is presumably exogenous, compared to the choice of a hospital. ${ }^{4}$ I define health care markets in several ways to check the sensitivity of the results.

Overall, my results indicate that uninsured patients have statistically and economically significant effects on the health outcomes of insured heart attack patients. I find that eliminating uninsurance would reduce the number of insured heart attack deaths, in the average year from 1999 to 2006 , by 3-5\% depending on the market definition. The use of fixed effects methods alleviates concerns about time invariant factors biasing my estimates, but it does not eliminate the possibility of a bias arising from time-varying unobservable determinants of in-hospital heart attack mortality that are also correlated with the market uninsurance rate. While I cannot eliminate all sources of endogeneity, I provide evidence suggesting that the results are unlikely to be biased under a broad set of scenarios where the violation of the fixed effects assumptions might be of concern.

First, I examine the possibility of a reverse causality bias, such as when temporarily low

\footnotetext{
${ }^{3}$ In the absence of small area population based uninsurance measures, I use measures based on patient discharges and use "uninsured" and "uninsured discharges" interchangeably. In section 4.2, I provide evidence showing that these measures are successful in capturing the year-to-year variations in the population uninsurance.

${ }^{4}$ Results at the hospital level will be shown as well.
} 
quality hospitals attract uninsured patients over time. Second, I investigate whether patient composition effects (e.g., when healthier insured patients leave temporarily high uninsurance areas) might be driving the results. Third, I investigate the possibility of a sample selection bias resulting from strategic changes in hospital admission or discharge policies that are correlated with the uninsurance rate. Fourth, I explore the issue of unobserved trends due to local shocks, such as county outreach programs or economic shocks, that affect both heart attack survival risk and the market uninsurance rate. In all cases, I provide evidence that the baseline results are unlikely to suffer from an upward bias. Finally, using the informal framework suggested by Altonji et al. (2005), I estimate that selection on unobservables would need to be 2.5-7 times stronger than selection on observables in order to attribute the entire effect of uninsurance to selection bias, which is highly unlikely.

I supplement these analyses with further robustness checks. I show that the results are robust to using alternative measures of uninsurance that take into account uninsured patient costs, length of stay, admission source and diagnostic characteristics, as well as the selection of hospitals in the analysis sample, alternative insured patient outcomes and model selection. My analysis on the heterogeneity of the results suggests that the effects are much larger for public and not-for-profit hospitals, and small in magnitude and statistically insignificant for for-profit hospitals. Since public and not-for-profit hospitals are more likely to be financially constrained, these results provide a first suggestive evidence that the main channel by which the uninsured affect insured health outcomes is through finances.

In the last section of the paper, I further probe the mechanisms leading to the observed spillover effects. Using panel data models as in the baseline specification, I find that the uninsured affect insured heart attack outcomes mainly through increases in hospital uncompensated care costs. I provide evidence that these effects are not driven by strategic price 
increases in hospitals that experience a surge in the uninsured. Data limitations constrain my capacity to check how hospitals change their provision of care to insured AMI patients in response to reduced revenues as information on many important dimensions of care are not collected. For that reason, I focus on a set of variables pertaining to the provision of heart attack care for which reliable information is available: hospital staff and procedures. The evidence I have suggests a modest increase in the quantity of cardiac services without a corresponding increase in hospital staff. This finding is consistent with strategic hospital behavior aimed at dissipating the negative financial effects of uninsurance through changes in the provision of care.

This paper makes several contributions. First, as described above, most of the existing literature on the community effects of uninsurance has focused on its impact on access to health care. The few studies that looked at quality of care focused on self-reported measures, such as the ability to get referral to a specialist, trust in the patient's doctor or self-satisfaction with the health care provider. These patient-satisfaction quality measures are often criticized because they may reflect factors that are not directly related to clinical quality (Office of the Statewide Health Planning and Development, 2002). I use an outcomeof-care quality measure instead and examine if the uninsured affect insured patient health outcomes. Second, most of the studies in the previous literature relied on market-level analyses. However, the level of aggregation in these studies does not permit examining if the uninsurance rate is increasing in one region of the market while outcomes are deteriorating in another. For that reason, this paper takes the hospital as the unit of analysis. Finally, the previous literature did not provide any empirical evidence on the mechanisms that lead to the observed spillovers. ${ }^{5}$ I examine some of the plausible mechanisms that explain the

\footnotetext{
${ }^{5}$ One notable exception is Pauly and Pagán (2009) where the authors estimate the effects of both the community uninsurance rate and the community-level charity care on insured adults' access to health care
} 
relationship between the uninsured and insured health outcomes.

My results pertain directly to the current policy debate on health care. According to Congressional Budget Office (2010), under the recent health care reform an estimated 23 million nonelderly Americans will still be without insurance coverage by 2019. In addition, the health care reform includes provisions to cut Disproportionate Share Payments, ${ }^{6}$ the major source of funding for hospitals that serve a disproportionately high number of Medicaid and uninsured patients. Under these circumstances, the problem of the uninsured is likely to keep its place at the center stage of policy debates in the coming years.

The remainder of the paper is organized as follows. Section 2 presents a background on the treatment of heart attack patients and financing and delivery of care to uninsured people in California. Section 3 outlines the empirical framework, while section 4 introduces the data and provides descriptive statistics. The results are presented in section 5 along with a discussion on heterogeneous effects, robustness checks and mechanisms. Finally, section 6 concludes.

\section{Background}

\subsection{The Treatment of Heart Attack Patients}

A heart attack is an acute event that occurs when the heart gets an insufficient supply of blood due to blockage in the coronary arteries. Unless immediate care is provided, part of and on their self-reported evaluation of the quality of care. Pauly and Pagán (2009) argue that the community uninsurance measure captures non-pecuniary spillovers, whereas the community-level charity care captures pecuniary spillovers. It is worth noting that their study focuses on privately insured working age adults. To the extent that the mechanisms for spillovers differ for the elderly or the communities where they reside, my results add to our understanding of these mechanisms.

${ }^{6}$ See Section 3133 of the Patient Protection and Affordable Care Act, available at http://democrats . senate.gov/reform/patient-protection-affordable-care-act-as-passed.pdf, accessed on July 5, 2010 . 
the heart muscle dies within hours. It is a common cause of death for both men and women in the US with 668,447 reported hospitalizations in $2006^{7}$ and over 900,000 incidences across the nation every year (Spertus et al., 2003). Unless the attack results in sudden death, the patient is admitted to a hospital for treatment.

The 90 days following the onset of a heart attack are generally accepted to be the acute phase during which patients are administered treatments that can be broadly classified into two categories. ${ }^{8}$ Medical management relies on drug therapies and nonsurgical interventions. Commonly employed medical management methods include the use of thrombolytic drugs to dissolve the clot that caused the heart attack and the administration of aspirin to prevent further clotting.

Invasive treatments include catheterization and revascularization procedures. Catheterization is an intensive diagnostic procedure that checks the blood flow to the heart. A catheter is inserted and guided through the large arteries of the body and an X-ray dye is injected through the catheter making the blood flow visible. If significant blockage is detected, the patient may receive a revascularization procedure. The most common revascularization procedures are bypass surgery (coronary artery bypass graft, CABG) and angioplasty (percutaneous transluminal coronary angioplasty, PTCA). Bypass is a major open heart surgery that involves using a segment of a healthy blood vessel from another part of the body to reroute blood flow around the blocked part of the coronary artery. Angioplasty is a less invasive procedure where blood flow is restored by inflating a catheter balloon in and around the blockage. This procedure has become increasingly popular in the mid-1990s with the introduction of coronary stents, small wire tubes that keep the arteries open.

\footnotetext{
${ }^{7}$ Calculated from the HCUP data, available at http://hcupnet.ahrq.gov/, accessed on August 16, 2008.

${ }^{8}$ For more detail on heart attack treatment options, see Cutler et al. (1999). For a description of changes in heart attack treatment during the last century, see McClellan and Kessler (1999); Heidenreich and McClellan (2001).
} 
Although the treatment options described above provide the main skeleton of heart attack care during the acute phase, the full course of treatment includes many other components: quality of floor-to-door care (care provided between the time of the heart attack and hospital arrival), duration to vital treatments, quality of cardiac care equipments, availability of monitoring technologies, expertise and skill of the physicians caring for the patients, degree of specialization of cardiac nurses etc. It is the combination of all these factors that produce the health outcome of the heart attack patient.

Uninsurance could influence the provision of both intensive and non-intensive heart attack care. On the one hand, intensive treatment options have high fixed costs of adoption and high variable costs per use. Hospitals that bear high uncompensated care costs due to the uninsured may find it difficult to adopt these high-tech services or they may have to provide lower quality intensive care treatment to reduce their costs. On the other hand, intensive services generally have higher reimbursement rates. Hospitals may increase the provision of these services in order to cross-subsidize the cost of care to the uninsured. Similarly, hospitals could reduce the amount of care provided by specialized personnel since skilled workers have higher labor costs. Such a strategy could lead to delays in the provision of crucial procedures or detections of complications. Uninsurance could also affect the provision of medical management. For example, hospitals may hire lower quality physicians or reduce their overall staff to reduce their costs which may lead to delays in the administration of drug therapies. I explore some of the potential mechanisms leading to the observed spillover effects of uninsurance in section 5.4. 


\subsection{Institutional Background}

According to the California Welfare and Institutions Code (1933), counties have a statutory obligation to provide care to the medically indigent. ${ }^{9}$ The current organization of the county medically indigent programs emerged in the early 1980s when the state legislature eliminated medically indigent individuals from California's Medicaid program, Medi-Cal, and transferred responsibility for them to counties. Since then the 24 largest counties manage their own distinct Medically Indigent Service Programs (MISP) and the 34 smaller rural counties participate in the centralized County Medical Services Program (CMSP).

Despite their historical role as provider of last resort of health care services, medically indigent programs cover only a third of the uninsured population in California (Insure the Uninsured Project, 1998). The lack of reliable data on the funding and expenditures of the county indigent programs makes it difficult to analyze how they fare relative to the cost of the care provided to these individuals. However, health care providers frequently argue that reimbursement for indigent care is far less than its cost.

The responsibility of the remaining two thirds of the uninsured mainly falls on the hospitals. The Emergency Medical Treatment and Active Labor Act (EMTALA, 1986) requires hospitals participating in Medicare to provide medical screening to all patients seeking emergency care. If a patient is determined to have an emergency condition, the hospital is then expected to stabilize the person, regardless of income or insurance status. Some hospitals have additional mandates to provide care to uninsured patients. These include Hill-Burton Act (1946) participants that received loans and grants for construction projects in return for their agreement to provide care to those who are unable to pay and not-for-profit hospitals that must provide community benefits in exchange for their tax-exempt status.

\footnotetext{
${ }^{9}$ For more detail on the institutional background, see Kelch $(2004,2005)$; Insure the Uninsured Project (2007).
} 
The costs of care to these individuals are born mutually by the patients as out-of-pocket payments and by the hospitals as uncompensated care. Uncompensated care costs in California reached $\$ 5.1$ billion in 2003 (Price Waterhouse Coopers, 2007), and cost-adjusted uncompensated care costs represented $3-7 \%$ of operating expenses in 2008, depending on the hospital type (California Health Care Foundation, 2010). Hospitals receive partial reimbursement for their uncompensated care costs through various federal and state supplemental payments. In California, the majority of the funds come from the Medicaid Disproportionate Share Hospital Payment Program (SB 855), a program jointly administered by the federal and state governments aiming to help hospitals that serve a disproportionately high number of Medi-Cal and uninsured patients. ${ }^{10}$ However, because SB 855 has a structure that makes Medicaid patients financially more attractive than the uninsured ${ }^{11}$, some believe that the "DSH mechanism places the need for appropriate and efficient care to Medi-Cal recipients at odds with the desire to supplement the cost of care for the indigent" (Huen, 1999, p. 8) and that only a small fraction of these supplemental payments are actually used to cover the uncompensated care costs to uninsured patients. Furthermore, Baicker and Staiger (2005) found that the state of California was able to capture most of the SB 855 funds so that hospitals had almost no change in their resources.

\footnotetext{
${ }^{10}$ Other funds related to the uninsured come from the Emergency Services and Supplemental Payments Program (SB 1255), the Small and Rural Hospital Supplemental Payments Program (AB 761), and the Tobacco Tax and Health Protection Act (Proposition 99). SB 1255 is a DSH-type program that allows qualified hospitals to negotiate with California Medical Assistance Commission (CMAC) to receive additional payments. AB 761 provides supplemental funds to rural hospitals with standby emergency rooms that are not eligible for SB 1255. Finally, Proposition 99 allocates 35 percent of the generated revenues to hospitals and physicians to reduce uncompensated care costs. These programs and their associated funds, however, are much smaller when compared to the reimbursements under SB 855 (Insure the Uninsured Project, 2007).

${ }^{11}$ A hospital qualifies for SB 855 if (1) the number of its Medicaid inpatient days is at least one standard deviation above the statewide mean, or (2) its revenues from low-income utilization exceed 25 percent of its total revenues. Qualified hospitals receive a per diem rate for all of their Medi-Cal patient days. Although uninsured patients can affect the per diem rate the hospital receives, they do not contribute to the number of days used in the calculation of the SB 855 reimbursement.
} 
Overall, the system financing the provision of medical care to the indigent and uninsured populations in California is very fragmented. Hospitals are legally required to provide services to these individuals but there are no guarantees that they will receive reimbursement for their provision of care. As a result, hospitals often face significant revenue losses due to uncompensated care costs and this may affect the quantity and quality of care provided to all patients.

\section{Empirical Strategy}

I am interested in examining the causal effect of uninsurance on insured health outcomes. The primary challenge stems from the endogenous choice and location of hospitals, indicating that uninsurance rates may be high in areas where insured health outcomes are worse for other, unobserved reasons. For example, insured patients residing in high uninsurance areas may have unobservable characteristics that predispose them to worse health outcomes. Similarly, hospitals in high uninsurance areas may provide worse quality of care that cannot be captured with observable information. Failing to account for this could lead to a spurious correlation between uninsurance rates and insured health outcomes. In order to account for this potential endogeneity, I identify the effects of uninsurance on insured patients using panel data models. The key equation of interest can be described as:

$$
Y_{j t}=\alpha+\beta U N I N S_{j t}+\delta X_{j t}+c_{j}+\nu_{t}+\epsilon_{j t}
$$

where the unit of observation is hospital $j$ in year $t . \quad Y$ is the average health outcome of interest for insured patients, UNINS is a measure of uninsurance, $X$ includes average demographic and clinical characteristics of the insured patient population studied as well 
as observable hospital characteristics, $c$ is a hospital fixed effect that corrects for hospital specific factors as well as selection into hospitals based on unobserved characteristics that are time-invariant or that change slowly over time, $\nu$ is a set of year dummies that controls for overall changes in the health outcome over the sample period and $\epsilon$ is the idiosyncratic error. I provide detailed information on each of these variables in section 4, after describing the data sources. Since the main independent variable is an aggregate measure, this grouplevel analysis is preferred to a patient-level regression to avoid the danger of producing low standard errors and exaggerating the significance of the effects of uninsurance (Moulton, 1986, 1990). In order to recover the coefficient estimates from an individual-level model, the regressions are weighted by the size of the studied insured population in the hospital.

The key identifying assumption of this model is that the uninsurance rate is uncorrelated with unobserved factors that vary over time and are, in turn, correlated with the outcome. ${ }^{12}$ If this is true, then $\beta$ represents the causal effect of the uninsured on insured patients. This assumption, while commonly made in panel data applications, is non-trivial as there are many time-varying factors that could affect both patient outcomes and uninsurance rates. For example, if temporarily low quality hospitals attract uninsured patients over time (reverse causality) or if healthier insured patients exit temporarily high uninsurance areas (patient composition effects), the fixed effects estimates will be upward biased. For that reason, I spend most of the results section discussing these and other potential scenarios under which the strict exogeneity assumption might fail and check whether they could drive the results.

\footnotetext{
${ }^{12} \mathrm{~A}$ key issue in fixed effects models is the source of the variation left in the variables after the fixed-effects transformation. In particular, we would like to know where the variation in the measure of uninsurance comes from. I will return to this issue after discussing the measures of uninsurance in section 4.2.
} 


\section{Data}

To assess the effects of uninsurance on insured heart attack patients, I combine information on California hospitals from several sources for the period 1999-2006. ${ }^{13}$ The main source, California Public Inpatient Hospital Discharge Data (PD), is an annual individuallevel dataset on every discharge from non-federal hospitals in California. It includes information on basic demographic characteristics of patients including age, sex, race, ethnicity and residential zip code. More importantly, the dataset provides extremely detailed clinical information. For every discharge, I have information on the five-digit ICD-9 $\operatorname{codes}^{14}$ of the principal and up to 24 secondary diagnoses and procedures and the DRG code ${ }^{15}$ of the case file, as well as the admission quarter, source of admission and type of discharge location. This allows me to precisely measure the outcomes of heart attack patients while effectively controlling for their underlying health conditions that might predispose them to adverse outcomes. Finally, the PD data also includes information on the primary expected source of payer which I employ to measure uninsurance. ${ }^{16}$

The second source of data is the California Annual Hospital Utilization Files. This yearly hospital level dataset provides information on each hospital's license type, location (address, city, zip code), teaching status and ownership type. I further use the address information to construct spatial Geocode data (latitude and longitude) on hospitals that is used to

\footnotetext{
${ }^{13}$ For more detail on these data sources, see http://www.oshpd.ca.gov/.

${ }^{14}$ The International Classification of Diseases (ICD) is published by the World Health Organization and is used to assign codes to diagnoses and procedures associated with inpatient and outpatient utilization.

${ }^{15}$ Diagnosis-related group (DRG) is a system that classifies patients with similar hospital resource use (based on their diagnostic, therapeutic and demographic characteristics) into groups for reimbursement purposes.

${ }^{16}$ To ensure patient confidentiality, some variables in the PD are masked for certain observations. Masked variables include, in the order of masking: age in years, ethnicity, race, sex, categorical age variables, residential county code, admission quarter and patient zip code. In my empirical analysis, I include indicators for masked observations on any of the variables. Note that expected primary payer and clinical variables are never masked.
} 
define health care markets. Finally, I use data from California Annual Hospital Disclosure Files and National Hospital Discharge Survey when examining the plausible mechanisms whereby the uninsured impact insured in-hospital AMI mortality. California Annual Hospital Disclosure Files include detailed balance sheet information on hospitals as well as information on services and staff. National Hospital Discharge data is used to determine commonly provided procedures to heart attack patients.

In the empirical analysis, I focus on general acute care hospitals operating continuously from 1999 through 2006 that provided care to insured adult heart attack patients at any time during the sample period. This leaves 2,685 hospital-year observations on 352 hospitals that provided care to 426,459 adult insured heart attack patients.

\subsection{The Outcome Variable}

The outcome variable is the in-hospital heart attack mortality rate of insured patients aged 18 and above whose discharge information is not missing. ${ }^{17}$ Examining the impact of uninsured patients on the heart attack mortality of insured patients is interesting for several reasons. As discussed in section 2.1, heart attack is a common cause of death among both men and women. It is also a health event for which the cost of treatment has increased substantially over time (McClellan et al., 2002). Hence, heart attacks are widely studied in the medical literature and in economics (e.g. Cutler and Berndt, 2001; McClellan and Kessler, 2002; Murphy and Topel, 2003). However, no study has yet explored the effects of uninsured patients on the health outcomes of insured heart attack patients.

AMI is also a health condition for which the evidence suggests that high mortality may be associated with insufficient quality of care. McClellan and Staiger (1999) found that heart

\footnotetext{
${ }^{17}$ In section 5.2.6, I show that the results are robust to using alternative measures of quality.
} 
attack mortality correlates well with other quality indicators. Similarly, some researchers argue that the wide treatment options for heart attack patients make it possible for health care providers to vary the quality of care (Farsi, 2004). As such, heart attack mortality has been used as a quality indicator by many policy makers (e.g., the Texas Department of State Health Services and the Centers for Medicare and Medicaid Services) and researchers (e.g. Burgess et al., 2004; Propper et al., 2007).

A third advantage of heart attack mortality as an outcome variable is that it is superior to other adverse outcomes from the point of view of measurement. Heart attack, as a diagnosis, is less likely to be affected by coding differences across hospitals. In addition, the timing of death is unambiguous, whereas the diagnosis of other adverse outcomes such as infections conveys less information about the timing of the event. For example, the patient could have had the infection before being admitted to the hospital but access to care for some other diagnosis could have made the detection of the infection possible.

Finally, because it is a severe medical condition that requires urgent care, the endogenous selection of heart attack patients into hospitals based on health status or other unobservable characteristics is less of a concern. In addition, in the case of heart attacks, hospitals may not be able to select patients based on their survival risk as EMTALA (1986) requires that they stabilize every patient with an emergency condition. The fact that using heart attack patients minimizes selection bias led several other researchers to focus on this sample in other contexts. ${ }^{18}$

Several limitations of the outcome variable should be noted, however. First, annual inpatient AMI mortality is not reliable when hospitals treat relatively few patients. This

\footnotetext{
${ }^{18}$ Cutler et al. (2001) examine the effects of managed care on medical productivity, Shen (2002) studies the impact of hospital ownership choices on patient health outcomes, and Propper and Reenen (2010) examine whether the regulation of nurse wages affects the quality of hospital care in the UK.
} 
"small denominators" problem leads to misclassification of the quality of hospitals (McClellan and Staiger, 1999) which amounts to measurement error in the outcome variable, reducing the precision of the estimates. This concern is alleviated by the fact that the regressions are weighted by the size of insured AMI population at the hospital and, as I show in section 5.1, the baseline estimates are statistically significant at conventional levels. Furthermore, I check the robustness of the estimates to various sample selection criteria and to estimating long difference models to alleviate the potential measurement error in the outcome variable.

A second, and arguably more important, concern in using in-hospital mortality rates as a quality indicator is due to the fact that hospitals have some discretion in their admission or discharge policies (Farsi and Ridder, 2006). In order to alleviate such a concern, many studies use long-term mortality rates that capture deaths outside the hospital or adopt additional quality indicators such as re-admission rates. Since my data come from the public use files, I cannot link patients over time or to death records outside the hospital. However, evidence from previous studies indicates that this may be a relatively insignificant issue for the case of AMI mortality. In their examination of 3954 US hospitals during 1984-1994, McClellan and Staiger (1999) [p. 25] conclude that "for AMI, the signal ratio for 7-day mortality is higher than for 30-day mortality, and much higher than for 365-day mortality. All three measures have roughly the same signal, but 7-day mortality has less estimation error because overall mortality rate is lower at 7-days; longer-term outcomes largely add pure noise[...] Thus, it appears that short-term mortality measures are most useful for AMI." In my sample, the mean and median length of stay for insured AMI patients are a little over 5 days, lending support to the validity of in-hospital mortality as a measure of quality. Similarly, using a sample of patients with congestive heart failure from 30 hospitals in northeast Ohio during 1992-1994, Rosenthal et al. (2000) do not find any evidence of a bias in in-hospital mortality 
rates due to differences in discharge practices. Despite this evidence, I devote a significant portion of the results section to examining a potential bias due to strategic changes in hospital admission or discharge policies that are in turn correlated with the uninsurance rate.

\subsection{Measures of Uninsurance}

The main explanatory variable of interest measures the exposure of insured patients in each hospital to uninsurance. My preferred measure is the fraction of uninsured discharges in the health care market of a hospital because the choice of a health care market is presumably exogenous, compared to the choice of a hospital. However, I also provide results using the fraction of uninsured discharges at the hospital itself. ${ }^{19}$

Measuring the fraction of uninsured patients in a health care market requires defining the insurance status of a patient as well as the appropriate empirical health care market for a hospital. I classify a patient as uninsured if the primary expected payer is one of the following: County Indigent Program, Other Indigent program, self-pay, or other. I include patients covered by indigent programs in the definition because hospitals in general incur a net loss for providing care to these individuals. ${ }^{20}$ Following Garnick et al. (1987) and Gruber (1994), I define the health care market in two ways: a geopolitical boundaries approach, and a fixed-radius approach. ${ }^{21}$

\footnotetext{
${ }^{19}$ Since population insurance information is not available at the level of disaggregation used in this paper, I cannot use the fraction of uninsured individuals residing in the health care market of a hospital. However, a comparison of the population based state uninsurance rate from the CPS with the measure based on discharges from the patient data, provided in Figure A1 in the appendix, shows that the latter is successful in capturing the year-to-year variations in the population uninsurance.

${ }^{20}$ The patient's primary expected payer may be a noisy measure of the actual payer. However, since I use the same data to calculate the outcome variables, measurement error in these data should not bias my estimates. This way of defining the uninsurance status is common in the literature. See, for example, Currie and Fahr (2004).

${ }^{21}$ Market uninsurance rates are calculated as the fraction of uninsured discharges from all general acute care hospitals in that market definition rather than the fraction among hospitals that provided care continuously during 1999 to 2006.
} 
The geopolitical boundaries approach defines the health care market as the county, so the main independent variable is given by the fraction of uninsured discharges in the county. However, it is likely that hospitals located close to county borders attract patients located in neighboring counties, whereas hospitals located in really large counties such as Los Angeles do not attract all the patients in their county. Motivated by this idea, the fixed-radius approach defines health care markets as a fixed mile radius area around each hospital. I use a 5-mile and a 10-mile radius to define the health care market of each hospital and calculate the fraction of uninsured discharges among all the hospitals located within that area. Since appropriate measures of radius for urban and rural hospitals might not be the same, I supplement these market definitions with a third one where I define the market radius depending on hospital location. In particular, I define the market of rural hospitals to lie within a 10 mile longer radius than for urban hospitals, using a 5 (10) mile radius for urban hospitals while using 15 (20) miles for rural ones.

One point worth mentioning is the appropriateness of market uninsurance measures as instruments for the hospital measure of uninsurance. Since market and hospital measures of uninsurance are correlated with each other, if one believes that market uninsurance rates impact the health outcomes of insured patients at the hospital only through their effect on the share of uninsured patients at the hospital, then one could employ an instrumental variables model using the market measures as instruments for the hospital one. Previous literature, however, suggests that hospitals are strategic agents (e.g. Gruber, 1994; Duggan, 2000; Dafny, 2005). For that reason, hospitals may expect their share of uninsured patients to increase when they see an upsurge in uninsurance in the neighboring hospitals in the health care market and change the quantity or quality of their own care in response. Such behavior would violate the exclusion restrictions required for instrument validity. 
Since I identify the effects of uninsurance on insured patients using panel data models, another point worth discussing is the source of variation in uninsurance rates. Multiple studies have documented that changes in uninsurance are closely tied to changes in employerprovided insurance. For example, Holahan and Cook $(2005,2008)$ find that the driver of uninsurance during 2000-2006 is the reduction in employer-provided insurance, especially among the small businesses and the self-employed. Variations in employer-provided insurance are, in turn, related to changes in health insurance premiums (Feldman et al., 1997; Chernew et al., 2005; Gilmer and Kronick, 2005) as well as changes in employment and economic conditions (Gruber and Madrian, 1997; Cawley and Simon, 2005).

The lack of data availability prevents me from documenting how the described determinants changed in California during the study period at the geographic-level used in this paper. However, the existing information on state-wide fluctuations sheds some light on what could have caused year-to-year variations in uninsurance. Jacobs and Graham-Squire (2009) report that the share of Californian adults who had employer-sponsored health insurance decreased from $61.7 \%$ in 2000 to $58.6 \%$ in 2007 . At the same time, Gabel et al. (2007) document that health insurance premiums in the small-group market in California rose more than 50 percent during 2003-2006 and estimate that the average premiums in the individual market increased by more than 20 percent between 2002 and 2006 . Unemployment, on the other hand, increased steadily from $4.9 \%$ in 2000 to $6.8 \%$ in 2003 after which it decreased in every year reaching $4.9 \%$ in $2006 .{ }^{22}$ Although the unemployed have the right to continue health insurance coverage under the Consolidated Budget Reconciliation Act (COBRA), many individuals cannot do so due to the prohibitively high costs. Gardner et al. (2009) note that the monthly COBRA premium for families was over $\$ 1,000$ in 2008 and

\footnotetext{
${ }^{22}$ The statistics are obtained from The Employment Development Department of State of California, available at http://www.labormarketinfo.edd.ca.gov/?pageid=164, accessed on February 17, 2011.
} 
that coverage costs can reach as high as $82 \%$ of the unemployment benefits.

Another factor contributing to movements in uninsurance is immigration. The chronically low health insurance coverage among immigrants, especially among non-citizen and undocumented individuals, is a well documented phenomenon (Carrasquillo et al., 2000; Goldman et al., 2005; Buchmueller et al., 2007). With 26\% of state population foreign-born (Hill and Hayes, 2003) and an estimated 2.4 million undocumented residents (Johnson, 2006), immigration is a particularly important dimension that needs to be taken into account in the context of California. According to the California Department of Finance, the state receives 73,000 illegal immigrants annually (Johnson, 2006). Since EMTALA (1986) prohibits inquiry into patients' citizenship status, it is not possible to measure to what extent changes in (illegal) immigration lead to changes in uninsured discharges but these individuals are likely responsible for part of that variation.

Finally, state and county reforms aimed at reducing uninsurance lead to fluctuations in uninsured discharges. During the past decade, California passed many incremental coverage expansions, such as Healthy Families Parents, Child Health and Disability Prevention Program Gateway, PacAdvantage and Federal Medicaid Hospital Waiver (Gardner et al., 2009), and it was home to many local initiatives such California Health Care Foundation's Step by Step program (Gardner and Mintz, 2008).

In summary, there are many causes for the observed year-to-year fluctuations in uninsurance. However, all of these represent changes that are potentially endogenous to insured health outcomes. For example, changes in health premiums and economic events likely have direct effects on insured health outcomes that are not channeled through changes in uninsurance. Similarly, immigrants choose their destinations based on economic and personal factors, some of which may be related to the quality of hospital care in those areas. Like- 
wise, state and county reforms to reduce uninsurance may be partly motivated by observed spillover effects. For that reason, I spend most of the results section investigating a potential bias arising from endogenous changes to uninsurance rates that might violate the strict exogeneity assumption.

\subsection{Control Variables}

In the empirical analysis, I control for a large set of observable variables. The first set of variables controls for the observable characteristics of insured heart attack patients. These include basic demographic information such as the distribution of age, race and ethnicity and gender. Most importantly, they include a comprehensive set of comorbidy measures that were present at admission to the hospital and that the medical literature found to be important predictors of in-hospital mortality (see Table A1 for the full list and Elixhauser et al. (1998) for more details). These comorbidy measures are conditions that are not directly related to the principal reason for hospitalization and provide information about the patient's underlying health status. To illustrate, a patient is recorded to have uncomplicated diabetes as comorbidity if any of the secondary diagnosis codes include the ICD-9 codes of diabetes (250.00-250.33) and the DRG code of the case is not diabetes (294-295). ${ }^{23,24}$

The second set of variables consists of observable hospital characteristics. Among these, I include the demographic and clinical characteristics of all the patients in the hospital as they

\footnotetext{
${ }^{23}$ Use of Elixhauser Comorbidities is similar in nature to other disease-related risk adjustments. See for example, Skinner and Staiger (2009). In addition, the findings are robust to using alternative measures of disease severity, such as the Charlson Index. Results are available from the author upon request.

${ }^{24}$ One concern is that these comorbidity variables may reflect differences in the intensity of screening across hospitals. Since I control for hospital fixed effects, time-invariant differences in screening are not a concern. However, if hospitals change their intensity of screening over time in a way correlated with uninsurance then the FE estimates will be inconsistent. In order to explore this issue, I examined if hospitals that were located in different quartiles of the distribution of uninsurance in the base year (1999) had differential evolutions in the prevalence of comorbidities and found no evidence for that. The results are available on request.
} 
might provide information about the quality of care provided. Other variables include total discharges, the total number of hospitals in the health care market - for each definition of the market (to control for competition), and the fraction of Medi-Cal patients in the hospital. ${ }^{25}$

\subsection{Descriptive Statistics}

Table 1 and Figure 1 provide means of observable characteristics for hospitals at different quartiles of the distribution of average annual changes in the 10/20-mile market uninsurance rate. AMI mortality and the characteristics of insured AMI patients are weighted by insured AMI discharges, the characteristics of overall patients are weighted by total discharges and the uninsurance rates and hospital characteristics are unweighted.

The first row shows that the hospitals experiencing the largest average annual changes have an average annual market change in uninsurance that is 0.83 percentage points greater than the hospitals in the bottom quartile. The next row shows that the average annual reduction in insured AMI mortality is lower in the top two quartiles, indicating a positive relationship between year-to-year variations in market uninsurance rates and insured inhospital AMI mortality. The next row shows that hospitals located in highest uninsurance markets, on average, experienced the largest yearly reductions in uninsurance rates. However, the change in market uninsurance rates seems to be unrelated to the average insured heart attack mortality at the hospital.

\footnotetext{
${ }^{25}$ In particular, vector $X$ in equation 1 includes observable characteristics of insured AMI patients, observable characteristics of all patients and observable hospital characteristics. The observable insured AMI characteristic include the share of insured AMI patients who are 18-34 years old, 35-64 years old, 65 years and above, female, Non-Hispanic white, Non-Hispanic black, Non-Hispanic other, Hispanic, admitted to the hospital in quarter $j(j=1, \ldots, 4)$, has the Elixhauser comorbidity $j(j=1, \ldots, 32)$, as well as the share that has masked observations for each of the variables subject to masking. Observable characteristics of all patients are constructed in the same way as in the case of insured AMI patients and include in addition the share of patients in Major Diagnostic Category $j(j=1, \ldots, 25)$. Finally, the observable characteristics of hospitals include the number of hospitals in the market, total discharges and the share of Medicaid patients in the hospital.
} 
Panel A compares observable demographic characteristics of insured heart attack patients. Although there are statistical differences across quartiles, looking at the magnitudes, insured AMI patients have fairly similar demographic characteristics irrespective of the average annual change in the market uninsurance rate. One noticeable difference is in the distribution of race and ethnicity and suggests that patients are not randomly distributed across hospitals. Figure 1(a) provides a similar comparison for observable health characteristics using the distribution of Elixhauser comorbidities. The figure shows that the general patterns of the fraction of insured AMI patients with each comorbidity are very similar across quartiles with almost overlapping distributions.

Panel B and Figures 1(b) and 1(c) provide similar comparisons of observable demographic and health characteristics for the overall patient population. The age and gender distributions are again found to be similar across quartiles, while the ethnicity and race distribution is different across quartiles. The figures suggest that the distribution of major diagnostic categories and Elixhauser comorbidities are also similar across different quartiles. The main difference is observed in the fraction of discharges related to pregnancy, childbirth and newborn-neonate conditions (MDC 14 and 15) where hospitals in the second quartile have the highest rates, and the hospitals in the first quartile have the lowest.

Finally, Panel C provides means of observable characteristics of hospitals. The panel shows that hospitals that had the largest average annual increase in market uninsurance were relatively more likely to be rural, not-for-profit and located in significantly less competitive areas. The table also suggests that uninsurance rates declined at the tails of the distribution of hospital size: the largest and the smallest hospitals, who provide the most and the least care to heart attack patients, respectively, experienced the largest reductions in average annual market uninsurance rates. These differences further show the importance 
of controlling for time-invariant unobserved characteristics of hospitals when examining the effects of uninsurance on insured inpatient AMI mortality.

In summary, the descriptive statistics suggest that there is a positive relationship between AMI mortality and market-level uninsurance, but that hospitals differ in their observable characteristics. Therefore, most of the econometric analysis checks whether the relationship between AMI mortality and market uninsurance is driven by these observed differences or by time-varying unobserved characteristics.

\section{$5 \quad$ Econometric Results}

\subsection{Baseline Results}

Table 2 presents the main results. Each column represents a different market definition. The first row provides summary statistics for the uninsurance rate, while the following rows provide marginal effects of uninsurance on the in-hospital mortality rate of insured AMI patients. Robust standard errors clustered at the county level are shown in parenthesis below coefficients. ${ }^{26}$ The regressions are weighted by the number of insured AMI discharges at the hospital.

In order to gauge the importance of time-varying characteristics, I first estimate in row 2 models with only hospital and year effects, and then in row 3 models that also include the variables denoted by $X$ in equation (1) (i.e., demographic and clinical characteristics of insured heart attack patients in the hospital, demographic and clinical characteristics of all the patients in the hospital and basic hospital characteristics). A comparison of these rows shows that the estimated effects are robust to the inclusion of time-varying observable

\footnotetext{
${ }^{26}$ The results are robust to clustering at the hospital level.
} 
patient and hospital characteristics. This suggests that we may be less concerned about a bias due to time-varying unobservable characteristics. I will return to this issue in more detail in section 5.2.

The results point to the existence of negative spillovers from the uninsured to insured heart attack patients in their health care markets. The fixed effects estimates reported in row 3 are statistically significant in all cases but the geopolitical market definition. For example, the estimate based on the 10/20 mile market definition implies that a one percentage point increase in the uninsurance rate within a 10 (urban)/20(rural) mile radius around a hospital is associated with an increase in the mortality rate of its insured heart attack patients by 0.071 percentage points. In 1999, a move from the worst to the best decile of the uninsurance rate based on the $10 / 20$ mile market definition was about 7.23 percentage points. The same year the insured in-hospital AMI mortality spread between the worst and the best deciles was about 7.46 percentage points. Thus, the estimated effect of uninsurance $(0.513$ percentage points) can explain 6.88 percent of this mortality spread. The results also indicate that eliminating uninsurance would reduce the number of insured heart attack deaths, in the average year from 1999 to 2006, by 129-210 depending on the market definition. These numbers roughly correspond to a 3-5\% reduction in the total number of insured AMI deaths in the average year.

\subsection{Threats to Internal Validity and Robustness}

The main results suggest that as market uninsurance rates go up, insured heart attack patients treated at hospitals within that health care market are more likely to die. The key impediment to interpreting these results as causal is the possibility of a bias due to timevarying unobservable determinants of inpatient heart attack mortality that are also correlated 
with the market uninsurance rate. Alternative explanations include reverse causality, patient composition effects, unobserved trends due to local shocks, or sample selection bias due to endogenous changes in hospital admission or discharge policies. The remainder of this section considers these explanations and presents results that check the sensitivity and heterogeneity of the baseline estimates.

\subsubsection{Reverse Causality}

The hospital fixed-effects analysis used in this paper corrects for selection into hospitals based on time-invariant unobserved characteristics or unobserved characteristics that change slowly over time. Nonetheless, we may be concerned of selection due to time-varying unobservables. For example, if temporarily low quality hospitals have certain unobserved characteristics (e.g., medical discount cards) that make them magnets to uninsured patients, then current uninsurance rates will be correlated with past outcomes violating the strict exogeneity assumption.

In order to address a potential bias arising from such a reverse causality, I estimate fixed-effects instrumental variable models (using the specification including all covariates) in which the actual uninsurance rate is instrumented with a predicted measure. I calculate the predicted the number of uninsured and of insured patients in hospital $j$ at year $t$ as a weighted average of zip code visits as follows: ${ }^{27}$

$$
\operatorname{Pred}_{j t}=\sum_{z=1}^{Z}\left(\frac{n_{j z 99}}{\sum_{j=1}^{J} n_{j z 99}} \sum_{j=1}^{J} n_{j z t}\right)=\sum_{z=1}^{Z} \frac{n_{j z 99}}{n_{z 99}} n_{z t}
$$

where $n_{j z t}$ is the number of uninsured or insured patients from zip code $z$ that go to hospital

\footnotetext{
${ }^{27}$ This strategy is similar in nature to the construction of the predicted number of Medi-Cal and uninsured patients in Duggan (2000).
} 
$j$ in year $t$. Intuitively, these measures represent the number of insured or uninsured patients a hospital would have discharged in each year, had its patient mix stayed the same as in 1999 (the base year). I use these predicted numbers to construct the predicted uninsurance rate in the market $\left(\operatorname{Pr} U N I N S_{j t}\right)$.

Table 3 provides the results from this analysis. Panel A reproduces the baseline estimates for reference, while Panel B reports results from the fixed-effects instrumental variable model. First-stage results, provided in the first row, show that predicted uninsurance rates are highly correlated with the actual ones. F-statistics from a Wald test that the estimated coefficient of the instrumental variable is equal to 0 are provided in brackets below the coefficient estimates. The statistics are significantly greater than 10 for all regressions, suggesting that the instrument has predictive power. The following row reports instrumental variable estimates of the effect of uninsurance using two-stage least squares. The IV results confirm the positive impact of uninsurance on insured AMI mortality for all market definitions, although the magnitudes are somewhat smaller and the effects are less precisely estimated. For example, the coefficient reported in column 6 implies that a one percentage point increase in the uninsurance rate within 10/20 miles around a hospital is associated with a 0.054 percentage point increase in its insured AMI mortality rate. Below the IV estimates, I provide for each market definition the Hausman statistic testing the null hypothesis that the baseline estimate and the IV estimate are equal and the associated p-value. The equality of the baseline and IV estimates cannot be rejected for any of the market definitions. Overall, the results in Panel B support the previously documented robust relationship where uninsurance increases a hospital's insured AMI mortality rate and suggest that a potential bias arising from reverse causality is unlikely. 


\subsubsection{Patient Composition Effects}

The next issue I consider is the possibility of a bias due to sorting of patients based on unobservable characteristics. For example, we may be concerned that insured patients who are healthy in unobservable ways exit temporarily high uninsurance markets, leading to a spurious correlation between the main independent variable and the outcome of interest. In order to examine this issue, I use a two stage regression model ${ }^{28}$ :

$$
\begin{aligned}
& Y_{j t}=\alpha_{s 1}+\delta_{s 1} X_{j t}+v_{1 j t} \\
& \hat{Y}_{j t}=\alpha_{s 2}+\delta_{s 2} U N I N S+c_{j}+\nu_{t}+v_{2 j t}
\end{aligned}
$$

where the first equation regresses the insured heart attack mortality in hospital $j$ at time $t$ on the observable characteristics described in section 4.3. The second equation regresses the predicted insured AMI mortality obtained in the first stage on the uninsurance rate, year and hospital fixed effects. If there is positive selection, i.e. if risky patients who are more likely to die in the event of a heart attack are more likely to show up at the hospital when the uninsurance rate increases, we would expect $\delta_{s 2}$ to be positive and statistically significant.

Panel $\mathrm{C}$ of Table 3 provides the coefficient estimates on UNINS from the second stage regression. The results are statistically insignificant for all market definitions except the hospital measure itself and the estimated correlations are very small in magnitude for all columns. This suggests that there is no evidence of patient sorting based on observable health characteristics and, to the extent that observable characteristics convey information about unobservable aspects, we may be less concerned about a bias arising from endogenous changes in patient composition.

\footnotetext{
${ }^{28}$ This two stage regression model is in the same spirit as the sorting model provided by Murphy and Topel (1990).
} 


\subsubsection{Sample Selection Bias}

Next, I turn to the possibility of a sample selection bias resulting from strategic changes in hospital admission or discharge policies that are correlated with the uninsurance rate. For example, hospitals characterized with temporarily high uninsurance may reduce their admission rates, resulting in a sicker patient mix and higher mortality rates over time. One common practice that could lead to such selection bias is hospital emergency room closure and ambulance diversion policies. It could be the case that hospitals that have overcrowded emergency rooms due to the uninsured admit only the most severe AMI cases and divert the others. This could impact estimates in two ways. First, diverted patients may not survive to the next hospital and thus might not show up in the inpatient dataset. Shen and Hsia (forthcoming) find that increased driving time due to emergency department closures shifts the composition of AMI patients to younger ages, suggesting that older patients die en route. Second, if the diverted patient's severity of illness gets worse, the patient might survive to the next hospital but die due to delayed treatment. Shen and Hsia (2011) find that if an emergency department closest to a patient's residence diverts ambulances for at least 12 hours on the day the patient has a heart attack, then that patient has increased long-term (30-day, 90-day, 1-year) mortality risk. To the extent that the patient is admitted to a hospital within a 10/20 mile radius of the first hospital, this would create a spurious correlation between the market uninsurance rate and insured AMI mortality.

In order to shed some light on this issue, I examine the relationship between the uninsurance rate and the presence and non-stop availability of an emergency room at the hospital. In particular, I estimate equation 1 by replacing the outcome variable with indicators of having an emergency-room at the hospital and the provision of 24-hour emergency services on premise. The results, provided in the first two rows of Panel D of Table 3, do not show 
any evidence that the market uninsurance rates impact emergency room services at the extensive margin. This result is consistent with recent findings in the literature (Hsia et al., 2011). These findings are further supported by the previous analysis on patient composition effects documenting the lack of a systematic relationship between uninsurance and the risk profile of insured AMI patients.

A second issue related to endogenous changes in hospital admissions concerns the paramedic care: if pre-hospital care in high uninsurance areas gets better over time, more patients may survive the trip to the hospital only to die post-admission leading to a spurious correlation between uninsurance and the outcome variable. It is difficult to address changes in the quality of paramedic care directly due to lack of data. However, to the extent that changes in hospital admission policies lead to the admission of sicker patients as the uninsurance rate goes up, we should observe that riskier insured AMI patients comprise a larger share of the insured AMI patients. The previous analysis on patient composition effects and the results provided in Panel $\mathrm{C}$ of Table 3 suggest that such a bias is unlikely. ${ }^{29}$

With regard to endogenous discharge policies, we may be concerned that hospitals that experience a temporarily low uninsurance rate discharge their insured AMI patients faster, leading to an upward bias in the baseline estimates. This is particularly a concern in California where several hospitals were investigated due to allegedly "dumping" homeless patients (Winton and Blankstein, 2007). Using a longer window (e.g. 30-day, 90-day or 1-year) following a coronary attack would solve this problem as one would capture post-discharge deaths as well as inpatient deaths. Since such a strategy is not feasible with my dataset, I first focus on the extensive margin to check if insured heart attack patients in temporarily

\footnotetext{
${ }^{29}$ In another robustness check, I examined the impact of excluding very short-term (less than one day) hospitalizations from the analyses since these individuals might represent the "marginal" patients who are most impacted by the quality of paramedic care. The results, available from the author, are virtually unchanged, confirming the original findings.
} 
low uninsurance hospitals are more likely to be routinely discharged to home. In particular, I estimate equation 1 by replacing the outcome variable with the share of insured AMI patients who are routinely discharged to home. The findings are summarized in the third row of Panel D. Although there is some evidence of a negative association between the uninsurance rate and the share of insured AMI patients who are routinely discharged, the effects are very small in magnitude (0.03-0.67\% at the mean) and statistically insignificant.

In the fourth row, I focus on the intensive margin and replace the outcome variable in the baseline specification with the average length of stay of insured AMI patients at hospital $j$ in year $t$. In this case, I find a statistically significant positive relationship between changes in uninsurance and insured AMI patients' average in-patient stay. However, the estimates are again very small in magnitude and indicate that as a hospital's market uninsurance rate goes up by one percentage point, the average length of stay among its insured AMI patients increases by $0.012-0.014$ days or a $0.23-0.27 \%$ increase at the mean. ${ }^{30}$

Finally, I turn to the issue of transfer patients. The problem is two-fold. First, a heart attack patient who gets transferred to another facility is (naturally) recorded as being alive and so hospitals that transfer out a lot of patients mechanically have lower mortality rates. Second, we may be concerned that transfer patients are different than non-transfer patients in terms of unobservable characteristics which make them more or less likely to die. If where patients get transferred is further correlated with the uninsurance rate, then the fixed effects estimates will be biased. In particular, if patients who are more likely to die get transferred to hospitals in high uninsurance markets, then my initial estimates would be upward biased. In the last two rows of Panel D, I examine if the uninsurance rate is systematically related

\footnotetext{
${ }^{30}$ Adding the average length of stay of insured AMI patients as a covariate to the baseline specification confirms this finding: the coefficient of uninsurance is virtually unchanged for all market definitions. The results are available from the author upon request.
} 
to the share of insured AMI patients who are transferred to another facility by replacing the outcome variable in the baseline specification with the share of insured AMI patients who are transferred to another facility. Row 3 examines transfers to other hospitals, including acute care hospitals, skilled nursing/intermediate care facilities (freestanding or a distinct part within another hospital), and other types of hospitals such as psychiatric, physical medicine rehabilitation, or chemical dependency recovery treatment centers. Row 4 examines all transfers, including those to another hospital, residential care facility or a home health service program. The estimates are small in magnitude and statistically insignificant, indicating no apparent relationship between transfer probability and uninsurance. Overall, the analysis in Panel D suggests that the baseline results are unlikely to suffer from an upward bias due to sample selection.

\subsubsection{Unobserved Trends}

The following problem I consider is the issue of unobserved trends due to local shocks that affect both heart attack survival risk and the uninsurance rate. For example, some counties might increase their public outreach and education programs over time. This could reduce the incidence of hospitalizations among uninsured populations and at the same time the likelihood of death among heart attack patients through increased preventive care, leading to an upward bias in the fixed effects estimates. Similarly, changes in the economic environment, such as the closing of a factory, could lead to violations of strict exogeneity assumptions. Since most of the local initiatives are concentrated at the county level, in order to explore this issue, I add a county specific time trend to the baseline empirical specification and check the sensitivity of the estimates. The results of this specification are provided in Panel E of Table 3. The new estimates are slightly smaller in magnitude but the qualitative implications 
are the same as the original fixed effects estimates, with uninsurance generally leading to statistically significant increases in insured inpatient AMI mortality.

\subsubsection{Selection on Observed and Unobserved Variables}

In order to explore the issue of a potential endogeneity bias within a general framework, in this section, I apply the informal model suggested by Altonji et al. (2005) to estimate the extent of selection based on unobservables relative to selection based on observables needed to wipe out the effects of uninsurance. ${ }^{31}$ The results are provided in Panel $\mathrm{F}$ of Table 3. Intuitively, the model starts by assuming that selection on unobservables is the same as selection on observables. Under this assumption, one can derive the bias in the estimated coecient of uninsurance using only information on observables when uninsurance has no eect on the health outcomes of insured heart attack patients (row 1, Panel F). In an unrestricted model where uninsurance is allowed to have an effect on the insured, I obtain the fixed effects coefficients listed in row 2 of Panel F. In order for these estimates to be entirely driven by selection on unobservables, the amount of that selection relative to selection on observables should be equal to the ratio of the coefficient to the estimated bias. This bias factor is reported in the last row. The estimated bias is found to be negative for the hospital and geopolitical market definitions. In cases when the estimated bias is positive, the results indicate that selection on unobservables would need to be 2.5-7 times stronger than selection on observables in order to attribute the entire effect of uninsurance to selection bias. This seems highly unlikely and thus lends further support to the previous analyses showing that the fixed effects results are unlikely to suffer from an upward biased.

\footnotetext{
${ }^{31}$ For more details see Altonji et al. (2005).
} 


\subsubsection{Additional Robustness Checks}

In Table 4, I provide results from additional sensitivity checks. All analyses are based on the full specification including all control variables. Panel A reproduces the baseline estimates for reference. In Panel B, I examine the robustness of the results to using alternative measures of uninsurance. The first row uses the fraction of uninsured patients residing in a hospital's health care market as the main independent variable, rather than the fraction of uninsured hospital discharges in that market. ${ }^{32}$ The results based on these measures are imprecise but they are all positive and reasonably close in magnitude to the original estimates.

To the extent that the uninsured affect insured health outcomes by increasing hospital uncompensated care, measures that take into account the costs of uninsured discharges may be more appropriate. ${ }^{33}$ The results based on alternative measures that use the fraction of market costs (Panel B, row 2) and length of stay (Panel B, row 3) that correspond to uninsured discharges are found to be similar to the original estimates.

The measure of uninsurance used under the distance based market definitions assigns equal weights to all hospitals in the market regardless of their relative distance to each other. However, a hospital's behavior may be more responsive to hospitals that are closer to it even within a given radius. The results are robust to using a weighted distance based measure (row 4, Panel B) where the hospital itself is assigned a weight of 1 and neighboring hospitals are assigned weights inversely proportional to their distances from that hospital.

In row 5 of Panel $\mathrm{B}$, I examine the effects of uninsured patients who are admitted to the hospital through the hospital's emergency department. This is an arguably more exogenous

\footnotetext{
${ }^{32}$ This measure only uses observations with unmasked in-state residential zip codes. When defining the distance-based measures, the latitude and longitude of the zip code's centroid were used.

${ }^{33}$ However, these measures may be endogenous if hospitals partly determine the costs of the uninsured by deliberately changing their treatment to reduce their financial burden. Patient charges are converted into costs using a cost-to-charge ratio based on the information in the Annual Financial Data.
} 
measure of uninsurance since hospitals may have less discretion over who they admit through the ER. Although the precision of the estimates is somewhat reduced, the magnitudes of the estimated effects are much larger and generally statistically significant.

Another issue regarding the measure of uninsurance is related to the diagnostic characteristics of uninsured patients. When calculating the fraction of uninsured, I include all uninsured patients regardless of their diagnosis. If uninsured heart attack patients crowd out resources available to other cardiac patients, then the estimated effects of uninsurance may be representing resource constraints faced by hospitals rather than true spillovers to the quality of care provided to insured patients. Therefore, the policy implications under this scenario would be different. In the last row of Panel B, I provide results from regressions that estimate the impact of uninsured patients who are not diagnosed with AMI and thus do not directly compete for resources with insured AMI patients. The results are almost identical to those using all uninsured patients.

Next, I turn to limitations of using annual heart attack mortality rate as an outcome. As mentioned before, annual inpatient AMI mortality is not a reliable measure of quality when hospitals treat relatively few patients. The "small denominators" problem is alleviated in this case since the regressions are weighted by the size of insured AMI population at the hospital. ${ }^{34}$ In order to shed more light in this issue, in Panel C, I check robustness to the choice of analysis sample. Following the guidelines of the Agency for Healthcare Research and Quality (2007), row 1 of Panel C restricts the sample to hospitals with at least 30 insured

\footnotetext{
${ }^{34}$ In order to provide some direct evidence on the issue, I also investigated the persistence in the classification of hospitals. In particular, I divided the hospitals into deciles based on their 1999 insured in-hospital heart attack mortality rates and checked how the ranking of the hospitals in the best decile changes over the sample period. I also checked the average difference in the insured AMI mortality between this group of hospitals and the rest of the hospitals in each year. I found that hospitals that were classified as best quality in 1999 were still more likely to be classified as such during the rest of the sample period and that the average insured AMI mortality is significantly lower among these hospitals throughout the period.
} 
heart attack patient discharges. The next row further restricts the sample to hospitals with at least 150 insured heart attack patients, while the last row of the panel provides results based on a balanced sample of hospitals which provided care to insured AMI patients for the entire period. In all cases, the results point to a robust effect of uninsurance on insured AMI mortality similar to the one found in the baseline model.

Panel D checks the robustness of the effects across different diagnoses. I consider insured in-hospital stroke and hip fracture mortality because they are two common reasons for admissions through ER, and like AMI mortality, they are included in the inpatient quality indicators developed by the Agency for Healthcare Research and Quality (2007). Although the results for hip fracture mortality are generally insignificant, estimated effects are positive for both health outcomes. This suggests that the spillover effects of the uninsured are not particular to heart attack patients.

Finally, in Panel E, I investigate the sensitivity of the results to alternative model specifications. Given that the outcome variable is by nature restricted to the unit interval, one might be concerned that a linear model might be a poor approximation. In order to address this issue, the first row provides estimates from a fixed effects fractional logit model. ${ }^{35}$ These results agree with those produced by the linear fixed effects specification. Row 2 of panel E provides estimates from a long difference model. To the extent that there is measurement error in the variables, the long difference model could alleviate the resulting bias as compared to a fixed effects model. The estimated effects are qualitatively similar but much larger in magnitude. The final row provides results from a lagged dependent variable

\footnotetext{
${ }^{35}$ This model assumes that the fraction of insured heart attack patients who die at the hospital, i.e. $Y$, has a logistic distribution. In this case, hospital fixed effects are accounted for by including the averages over time of explanatory variables for each hospital in a pooled cross section logit regression. Hence, the coefficients on level variables capture the deviations from the means. The marginal effects are calculated in the same way as in the case of a binary logit model. For more details, see Papke and Wooldridge (2007).
} 
model. Guryan (2004) argues that under positive (negative) selection and a positive treatment effect, a lagged dependent variable model would provide a lower (upper) bound for the treatment effect and a fixed effects model would yield an upper (lower) bound, if the conditions for either of the two models are satisfied. Thus, these results can be interpreted as a lower bound for the effects of uninsurance and provide evidence that the uninsured, if anything, select into low mortality hospitals further supporting the idea that my estimates do not suffer from an upward bias.

To summarize, in this section, I presented evidence that my results are unlikely to be driven by a broad range of alternative scenarios. I also showed that the main estimates are robust to a host of specification checks. While none of these tests are individually sufficient to claim that the main results are not biased, taken together they provide compelling evidence that this is unlikely.

\subsection{Heterogeneous Effects}

In this section, I examine the heterogeneity in the effects of uninsurance by hospital ownership and location. All analyses are based on the full specification including all control variables. The results are provided in Table 5. The first column shows the mean in-hospital AMI mortality of insured patients in the sample and the following columns present effects of uninsurance using different market definitions. Means of uninsurance rates by type of health care provider and market are shown in brackets below coefficient estimates. Panel A reports the results for the full sample for reference.

Panel B shows the effects by hospital ownership. First, note that public hospitals are located in areas with the highest uninsurance rates and not-for-profit hospitals are located in markets with the lowest uninsurance rates. Similarly, the fraction of uninsured discharges in 
a hospital are the largest for public hospitals and the lowest for not-for-profit hospitals. The average in-hospital mortality rates of insured heart attack patients are similar among public and for-profit hospitals but smaller among not-for-profit hospitals. Turning to regressions results, models based on hospital uninsurance rates (column 1) show that the effects are much larger for public and for-profit hospitals, and small in magnitude and statistically insignificant for not-for-profit hospitals. The results based on arguably less endogenous market measures, on the other hand, suggest that market uninsurance affects public and not-for-profit hospitals while for-profit hospitals do not seem to be affected by it. The point estimates in the remainder of the columns are positive and statistically significant in distancebased market measures for both public and not-for-profits hospitals. The magnitudes of the estimates in the not-for-profit sample are close to those in the full sample but the estimates in the public sample are consistently much larger: a one percentage point increase in the fraction of uninsured patients within a 10-mile radius around a hospital is associated with an increase in the in-hospital AMI mortality among insured patients of 0.133 percentage points for public hospitals as opposed to 0.064 percentage points for not-for-profit hospitals (see rows 1 and 3 of Panel B in column 4). The results for for-profit hospitals are in some cases negative but they are less precise and always insignificant.

Panel C compares the effects of uninsured patients by hospital location. The average insured inpatient AMI mortality and the market uninsurance rates are similar for these groups. The results in the urban sample are qualitatively similar to those in the full sample but the estimated effects are somewhat larger. For rural hospitals, the results are less precise but the magnitudes are larger than in the full sample, especially for geographically dispersed market definitions. For example, a one percentage point increase in uninsurance within 20 miles around a rural hospital is associated with a 0.362 percentage points increase in its 
insured AMI mortality rate.

In order to shed more light on the heterogeneity in the effects, I use the balance sheet information in the Annual Financial Disclosure Data and divide hospitals into quartiles based on the distribution of the debt to asset ratio in 1999. I find that $57 \%$ of the for-profit hospitals are located in the first quartile of this distribution, whereas only $17 \%$ of public hospitals and $13 \%$ of not-for-profit hospitals are in the first quartile. Similarly, only $14 \%$ of rural hospitals are in the bottom quartile, as compared to $28 \%$ of urban hospitals. ${ }^{36}$ These results indicate that spillovers are stronger when hospitals are more financially constrained and provide a first suggestive evidence on the hypothesis that the main channel by which the uninsured affect insured health outcomes is through finances.

\subsection{Mechanisms}

In this section, I aim to shed some light on the mechanisms leading to the observed spillovers on insured patient outcomes. ${ }^{37}$ All analyses are based on the full specification including all control variables. The results are provided in Table 6. In Panel A, I examine the effects of the uninsured on hospital uncompensated care costs. ${ }^{38}$ The coefficient estimates in row 1 imply that a one standard deviation increase in the uninsurance rate increases the hospital uncompensated care costs ranging from a low of $\$ 300,000$ for the 5 mile market definition to

\footnotetext{
${ }^{36}$ Public Hospitals (N=64) Q1: 17\%, Q2: 28\%, Q3: 19\%, Q4: 36\%. Not-for-Profit Hospitals (N=164) Q1: 13\%, Q2: 30\%, Q3: 32\%, Q4: 24\%. For-Profit Hospitals (N=77) Q1: 57\%, Q2: 10\%, Q3: 16\%, Q4: 17\%. Rural Hospitals (N=58) Q1: 14\%, Q2: 28\%, Q3: 34\%, Q4: 24\%. Urban Hospitals (N=247) Q1: 28\%, Q2: $24 \%$, Q3: $23 \%$, Q4: $25 \%$.

${ }^{37}$ In examining the mechanisms leading to the observed spillover effects, it is important to document that the selected channels do have an impact on AMI mortality. In order to shed some light on this, I ran separate regressions of insured AMI mortality on the selected channels and the remaining explanatory variables in the baseline regression (denoted by $X$ in equation 1 ). The results show a statistically significant correlation between insured AMI mortality and the same variables that have a statistically significant relationship with uninsurance. This further supports the claim that uninsurance impacts insured AMI mortality through these channels. The results are available from the author upon request.

${ }^{38}$ Uncompensated care costs are converted to $1999 \$$ using the Consumer Price Index for the West Region.
} 
a high of $\$ 1.2$ million for the geopolitical market definition, or around $3-13 \%$ at the mean.

One concern is that these estimates may reflect a potential bias due to hospital pricegouging, where hospitals increase their prices to uninsured patients. This is especially a concern in the case of California where major hospital chains were subject to a series of class action lawsuits on the grounds that they charged excessive medical fees to uninsured patients. ${ }^{39}$ In order to probe this possibility, in row 2 of Panel A, I use the relative price difference between uninsured and Medicare patients within a hospital as the dependent variable. Following Melnick and Fonkych (2008), I calculate the relative price difference as the percentage difference in collection ratios between uninsured and Medicare patients, where collection ratios are calculated as the share of patient charges that were actually collected (i.e. ratio of net revenues divided by gross charges). Using Medicare patients as the comparison group is preferred because Medicare pays the same net price for a given service across hospitals, and so the variation in relative price differences is due exclusively to variations in the price charged to the uninsured. The mean of the outcome variable is 0.18 , indicating that during the sample period the uninsured paid on average $18 \%$ higher prices than Medicare patients. However, regression results in the remaining columns show no evidence of price-gouging in response to an increase in uninsurance. For example, the coefficient estimate in column 3 suggests that a one percentage point increase in uninsurance within 5 miles around a hospital is associated with a 3.65 percentage points reduction in the price to the uninsured relative to Medicare patients. The estimates are consistently negative and statistically significant across all market definitions. Overall, the estimates reported in Panel A support the conjecture that the main channel whereby the uninsured affect the provision of care to insured patients is through reductions in hospital revenues.

\footnotetext{
${ }^{39}$ See Ostrov (2006); Darc (2007); Egelko (2007); Harvey (2007).
} 
Examining how heart attack treatment patterns change as a result of this increased financial burden is more challenging because of data limitations. As described in section 2.1, heart attack care has many dimensions and involves inputs from many sources. Changes to these factors all constitute plausible channels through which uninsurance affects insured in-hospital AMI mortality. Unfortunately data is not available on most of these variables. The remaining panels of Table 6 examine the impact of the uninsured on a set of variables pertaining to the provision of heart attack care for which reliable information is available: hospital staff and procedures. Data on hospital staff comes from the Annual Financial Data and includes information on the non-stop availability of physicians and anesthesiologists on premise, as well as the number of FTE registered nurses and active cardiologists. The set of procedures examined includes the most common ten procedures (at the three-digit ICD-9 codes) received by heart attack patients based on the National Hospital Discharge Survey for 1999-2006. The procedure use rates are calculated using the procedure codes in the Patient Discharge Data.

The results on hospital staff are provided in Panel B. The point estimates on physicians, anesthesiologists and cardiologists, provided in the first three rows, are consistently negative for all market definitions while estimates pertaining to the number of FTE registered nurses are positive. However, the magnitudes of the effects are very small in all cases. For example, the estimates in column 5 indicate that as the fraction of uninsured discharges within 5/15 miles around a hospital increases by one percentage point, the probability of it having physicians and anesthesiologists on-premise 24 hours goes down, on average, by 0.071 and 0.094 percentage points, respectively. Similarly, the hospital is predicted to reduce the number of cardiologists by approximately 0.03 doctors and increase its FTE registered nurses by 0.3 nurses. All of these estimates correspond to an effect of less than $0.5 \%$ at the mean. Overall, 
the results do not provide evidence of an impact of uninsurance on hospital staff.

Panel C presents the results on procedure rates. These estimates suggest that increases in market uninsurance rates are in general accompanied by an increase in procedure rates. For example, the coefficient estimates in column 4 show that a one standard deviation increase in the 5/15-mile market uninsurance rate (2.8 percentage points) increases the fraction of insured heart attack patients who receive angiocardiography (row 2) by 0.26 percentage points, compared to a mean of $48 \%$; nonoperative intubation of gastrointestinal and respiratory tracts (row 9) by 0.21 percentage points, compared to a mean of $7 \%$ and puncture of vessel (row 10) by 0.14 percentage points, compared to a mean of $6 \%$.

Taken together, these results imply that hospitals provide a greater quantity of cardiac services without increases to its cardiac care staff. This finding is consistent with strategic hospital behavior aimed at dissipating the negative financial effects of uninsurance through changes in the provision of care.

\section{Conclusion}

In this paper, I examine the impact of uninsured patients on the health outcomes of the insured focusing on the in-hospital mortality rate of insured heart attack patients. I implement panel data models using data from California hospitals for the period 1999-2006 and find that uninsured patients have an economically significant negative effect on the health of insured AMI patients. I find that eliminating uninsurance would reduce the annual number of insured heart attack deaths to those who are currently insured by 3-5\%. I present evidence suggesting that the main results are not driven by alternative explanations and that the main estimates are robust to a host of specification checks.

In the final section of the paper, I examine the mechanisms leading to the observed neg- 
ative spillover effects. My results indicate that the primary channel by which the uninsured affect insured heart attack outcomes is through increased hospital uncompensated care costs. Finally, consistent with much of the previous empirical literature studying hospital strategic responses to financial incentives, I find that hospitals increase the quantity of their cardiac services without changing cardiac care staff.

As high managed care penetration rates persist, third party reimbursement rates decline and hospitals are no longer able to shift the financial costs of the uninsured to insured patients in the form of increased premiums, understanding how hospitals may respond to high uninsurance rates to recover their losses becomes even more important. Taken together, my results suggest that policies aimed at addressing the issue of uninsurance may have additional benefits to insured patients residing in the same communities. 


\section{References}

Agency for Healthcare Research and Quality (2007), "Guide to Inpatient Quality Indicators," Report.

Altonji, Joseph G., Todd E. Elder, and Christopher R. Taber (2005), "Selection on Observed and Unobserved Variables: Assessing the Effectiveness of Catholic Schools," Journal of Political Economy 113, 151-184.

Baicker, K., and D. Staiger (2005), "Fiscal Shenanigans, Targeted Federal Health Care Funds, and Patient Mortality," Quarterly Journal of Economics 120, 345-386.

Buchmueller, Thomas C., Anthony T. Lo Sasso, Ithai Lurie, and Sarah Dolfin (2007), "Immigrants and Employer-Sponspored Health Insurance," Health Services Research 42, 286 310.

Burgess, Simon, Denise Gossage, and Carol Propper (2004), "Competition and Quality: Evidence from the NHS Internal Market 1991-1999," Journal of Public Economics 88, $1247-1272$.

California Health Care Foundation (2010), "California's Health Care Safety Net: Facts and Figures," Facts Sheet.

California Healthcare Foundation (2007), "Snapshot: California's Uninsured 2007," Online brief avalailable at http://www.chcf.org/topics/healthinsurance/index.cfm? subsection=marketoverview.

Carrasquillo, Olveen, Angeles I. Carrasquillo, and Steven Shea (2000), "Health Insurance Coverage of Immigrants Living in the United States: Differences by Citizenship Status and Country of Origi," American Journal of Public Health 90, 917-923.

Cawley, John, and Kosali I. Simon (2005), "Health Insurance Coverage and the Macroeconomy," Journal of Health Economics 24, 299315.

Chernew, Michael, David M. Cutler, and Patricia Seliger Keenan (2005), "Competition, Markets and Insurance," Health Services Research 40, 1021-1039.

Congressional Budget Office (2010), "Cost estimate for the amendment in the nature of a substitute for H.R. 4872, incorporating a proposed manager's amendment made public on March 20, 2010," Available at http://www.cbo.gov/ftpdocs/113xx/doc11379/ AmendReconProp.pdf, accessed on July 5, 2010.

Currie, Janet, and John Fahr (2004), "Hospitals, Managed Care, and the Charity Caseload in California," Journal of Health Economics 23, 421-442. 
Curtis, Rick, and Ed Neuschler (2009), "Affording Shared Responsibility for Universal Coverage: Insights from California," Health Affairs 28, 417-430.

Cutler, David, Mark McClellan, and Joseph Newhouse (1999), Measuring the Prices of Medical Treatments, chap. The Costs and Benefits of Intensive Treatment for Cardiovascular Disease, 34-71, Washington, D.C.: The Brookings Institution.

Cutler, David M., and Ernst R. Berndt, eds. (2001), Medical Care Output and Productivity, University of Chicago Press.

Cutler, David M., Mark McClellan, and Joseph P. Newhouse (2001), "How Does Managed Care Do It?" RAND Journal of Economics 31, 526-548.

Dafny, Leemore (2005), "How Do Hospitals Respond to Price Changes?" American Economic Review 95, 1525-1547.

Darc, Keith (2007), "Lawsuit over Scripps' Billing of Uninsured a Class Action Up to 100,000 Patients Could Receive Funds," San Diego Union-Tribune, 06/29/2007.

Duggan, Mark (2000), "Hospital Ownership and Public Medical Spending," Quarterly Journal of Economics 115, 1343-1374.

Egelko, Bob (2007), "Hospital Chain Agrees to Settlement," SFGate.com, 01/12/2007.

Elixhauser, Anne, Claudia Steiner, D. Robert Harris, and Rosanna M. Coffey (1998), "Comorbidity Measures for Use with Administrative Data," Medical Care 36, 8-27.

Farsi, Medhi, and Geert Ridder (2006), "Estimating the Out-of-Hospital Mortality Rate Using Patient Discharge Data," Health Economics 15, 983-995.

Farsi, Mehdi (2004), "Changes in Hospital Quality after Conversion in Ownership Status," International Journal of Health Care Finance and Economics 4, 211-230.

Feldman, Roger, Bryan Dowd, Scott Leitz, and Lynn A. Blewett (1997), "The Effect of Premiums on the Small Firm's Decision to Offer Health Insurance," The Journal of Human Resources 32, 635-658.

Gabel, Jon, Jeremy Pickreign, Roland McDevitt, Heidi Whitmore, Laura Gandolfo, Ryan Lore, and Katy Wilson (2007), "Trend in the Golden State: Small-Group Premiums Rise Sharply While Actuarial Values for Individual Coverage Plummet," Health Affairs 26, 488-499.

Gardner, Annette, Melissa Rodgers, and Ken Jacobs (2009), “Addressing California's Health Coverage Gaps: The Impact of National Health Care Reform," Berkeley Center on Health \& Family Security Policy Brief. 
Gardner, Annette L., and Patricia H. Mintz (2008), "Lessons From The Field: Expanding Health Insurance Coverage One County at a Time," Health Affairs 5, 1454-1460.

Garnick, Deborah W., Harold S. Luft, James C. Robinson, and Janice Tetrault (1987), "Appropriate Measures of Hospital Market Areas," Health Services Research 22, 69-89.

Gaskin, Darrell J., and Jack Needleman (2003), "The Impact of Uninsured Populations on the Availability of Hospital Services and Financial Status of Hospitals in Urban Areas," in A Shared Destiny: Effects of Uninsurance on Individuals, Families, and Communities, National Academy of Sciences.

Gilmer, Todd, and Richard Kronick (2005), "It's The Premiums, Stupid: Projections of the Uninsured Through 2013," Health Affairs Web Exclusive, 143-151.

Goldman, Dana P., James P. Smith, and Neeraj Sood (2005), "Legal Status and Health Insurance Among Immigrants," Health Affairs 24, 1640-1653.

Gruber, Jonathan (1994), "The Effect of Competitive Pressure on Charity: Hospital Responses to Price Shopping in California," Journal of Health Economics 13, 183-211.

Gruber, Jonathan, and Brigitte C. Madrian (1997), "Employment Separation and Health Insurance Coverage," Journal of Public Economics 66, 349-382.

Guryan, Jonathan (2004), "Desegregation and Black Dropout Rates," NBER Working Paper No. 8345.

Harvey, Carol (2007), "A New Age for the Medically Uninsured," BeyondChron.com, $01 / 29 / 2007$.

Heidenreich, Paul A., and Mark McClellan (2001), "Trends in Treatment and Outcomes for Acute Myocardial Infarction: 1975-1995," The American Journal of Medicine 110, $165-174$.

Hill, Laura E., and Joseph M. Hayes (2003), "California's Newest Immigrants," California Counts Public Policy Institute of California.

Holahan, John, and Allison Cook (2005), "Changes in Economic Conditions and Health Insurance Coverage, 2000-2004," Health Affairs Web Exclusive, 498-508.

(2008), "The U.S. Economy and Changes in Health Insurance Coverage, 2000-2006," Health Affairs 27, 135-144.

Hsia, Renee Y., Arthur L. Kellermann, and Yu-Chu Shen (2011), "Factors Associated With Closures of EmergencyDepartments in the United States," Journal of the American Medical Association 305, 1978-1985. 
Huen, William (1999), "Californias Disproportionate Share Hospital Program," Medi-Cal Policy Institute Background Paper.

Institute of Medicine (2002), Care Without Coverage: Too Little, Too Late, National Academy of Sciences.

(2009), America's Uninsured Crisis: Consequences for Health and Health Care, National Academy of Sciences.

Insure the Uninsured Project (1998), "California'S Uninsured: Programs, Funding And Policy Options," Background Paper.

(2007), "A Summary of Health Care Financing for Low-Income Individuals in California, 1998 to 2007," Background Paper.

Jacobs, Ken, and Dave Graham-Squire (2009), "No Recovery in Sight: Health Coverage for Working-Age Adults in the United States and California," Berkeley Center for Labor Research and Education Policy Brief.

Johnson, Hans P. (2006), "Illegal Immigration," Public Policy Institute Of California.

Kelch, Deborah Reidy (2004), "The Crucial Role of Counties in the Health of Californians: An Overview," California Health Care Foundation Background Paper.

(2005), "Caring for Medically Indigent Adults in California: A History," California Health Care Foundation Background Paper.

McClellan, Mark, and Daniel Kessler (1999), "A Global Analysis Of Technological Change In Health Care: The Case Of Heart Attacks," Health Affairs 18, 250-255.

McClellan, Mark, and Douglas Staiger (1999), "The Quality of Health Care Providers," NBER Working Paper No. 7327.

McClellan, Mark B., Nathan Every, Alan M. Garber, Paul Heidenreichand Mark Hlatky, Daniel P. Kessler, Joseph Newhouse, and Olga Saynina (2002), Technological Change in Health Care, chap. Technological Change in Heart Attack Care in the United States, 21-54, University of Michigan Press.

McClellan, Mark B., and Daniel P. Kessler (2002), Technological Change in Health Care: A Global Analysis of Heart Attack, University of Michigan Press.

Melnick, Glenn A., and Katya Fonkych (2008), "Hospital Pricing and the Uninsured: Do the Uninsured Pay Higher Prices?" Health Affairs Web Exclusive, 116-122. 
Moulton, Brent R. (1986), "Random Group Effects and the Precision of Regression Estimates." Journal of Econometrics 32, 385397.

(1990), "An Illustration of a Pitfall in Estimating the Effects of Aggregate Variables on Micro Units," Review of Economics and Statistics 72, 334-338.

Murphy, Kevin M., and Robert H. Topel (1990), Advances in the Theory and Measurement of Unemployment, chap. Efficiency Wages Reconsidered: Theory and Evidence, 204-240, New York: St. Martin's Press.

Murphy, Kevin M., and Robert H. Topel, eds. (2003), Measuring the Gains from Medical Research: An Economic Approach, University of Chicago Press.

Needleman, Jack, and Darrell J. Gaskin (2003), "The Impact of Uninsured Discharges on the Availability of Hospital Services and Hospital Margins in Rural Areas," in A Shared Destiny: Effects of Uninsurance on Individuals, Families, and Communities, National Academy of Sciences.

Office of the Statewide Health Planning and Development (2002), "Report on Heart Attack Outcomes in California: 1996-1998," California Hospital Outcomes Project.

Ostrov, Barbare Feder (2006), "Sutter Health Settles Lawsuit," San Jose Mercury News, 08/04/2006.

Pagán, José A., Lakshmi Balasubramanian, and Mark V. Pauly (2007), "Physicians' Career Satisfaction, Quality of Care and Patients' Trust: The Role of Community Uninsurance," Health Economics, Policy and Law 2, 347-362.

Pagán, José A., and Mark V. Pauly (2006), "Community-Level Uninsurance and the Unmet Medical Needs of Insured and Uninsured Adults," Health Services Research 41, 788-803.

Papke, Leslie, and Jeffrey M. Wooldridge (2007), "Panel Data Methods for Fractional Response Variables with an Application to Test Pass Rates," Working Paper.

Pauly, Mark V., and José Pagán (2009), "Spillovers of Uninsurance in Communities," Report submitted to the Institute of Medicine Committee on Health Insurance Status and Its Consequences.

Pauly, Mark V., and José A. Pagán (2007), "Spillovers And Vulnerability: The Case Of Community Uninsuranee," Health Affairs 26, 1304-1314.

Price Waterhouse Coopers (2007), "The Financial Health of California Hospitals," California Health Care Foundation Background Paper. 
Propper, Carol, Simon Burgess, and Denise Gossage (2007), "Competition And Quality: Evidence From The NHS Internal Market 1991-1999," Economic Journal 118, 138-170.

Propper, Carol, and John Van Reenen (2010), "Can Pay Regulation Kill? Panel Data Evidence on The Effect Of Labor Markets On Hospital Performance," Journal of Political Economy 118(2), 222-273.

Rosenthal, Gary E., David W. Baker, Donald G. Norris, Lynne E. Way, Dwain L. Harper, and Richard J. Snow (2000), "Relationships Between In-Hospital and 30-Day Standardized Hospital Mortality: Implications for Profiling Hospitals," Health Services Research 34, 1449-1468.

Sabik, Lindsay (forthcoming), "The Effect of Community Uninsurance Rates on Access to Health Care," Health Services Research .

Shen, Yu-Chu (2002), "The Effect of Hospital Ownership Choice on Patient Outcomes After Treatment for Acute Myocardial Infraction," Journal of Health Economics 21, 901-922.

Shen, Yu-Chu, and Renee Y. Hsia (2011), "Association Between Ambulance Diversion and Survival Among Patients With Acute Myocardial Infarction," Journal of the American Medical Association 305, 2440-2447.

(forthcoming), "Does Decreased Access to Emergency Departments Affect Patient Outcomes? Analysis of Acute Myocardial Infarction Population 1996-2005," Health Services Research .

Skinner, Jonathan, and Douglas Staiger (2009), "Technology Diffusion and Productivity Growth in Health Care," NBER Working Paper No. 14865.

Spertus, John A., Martha J. Radford, Nathan R. Every, Edward F. Ellerbeck, Eric D. Peterson, and Harlan M. Krumholz (2003), "Challenges and Opportunities in Quantifying the Quality of Care for Acute Myocardial Infarction," Circulation 107, 1681-1691.

Winton, Richard, and Andrew Blankstein (2007), "Law Would Bar Dumping Patients On The Street," Los Angeles Times, 02/22/2007. 


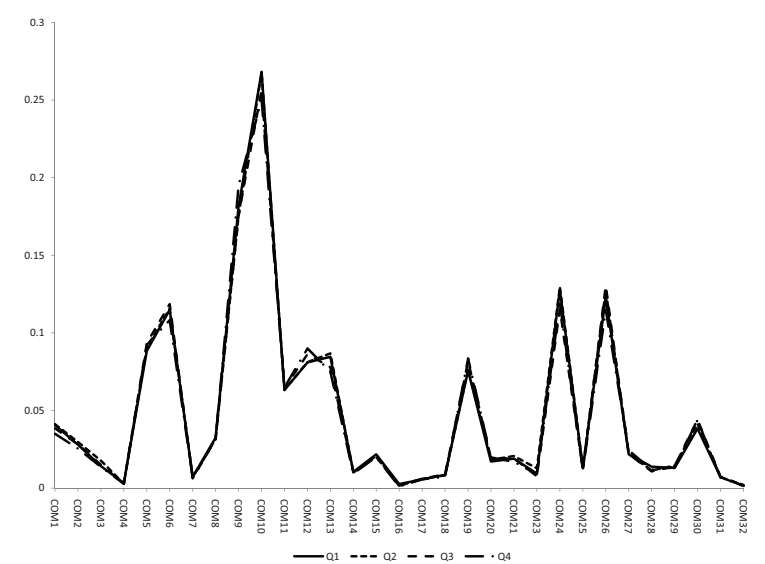

(a) Elixhauser Comorbidities: Insured AMI Patients

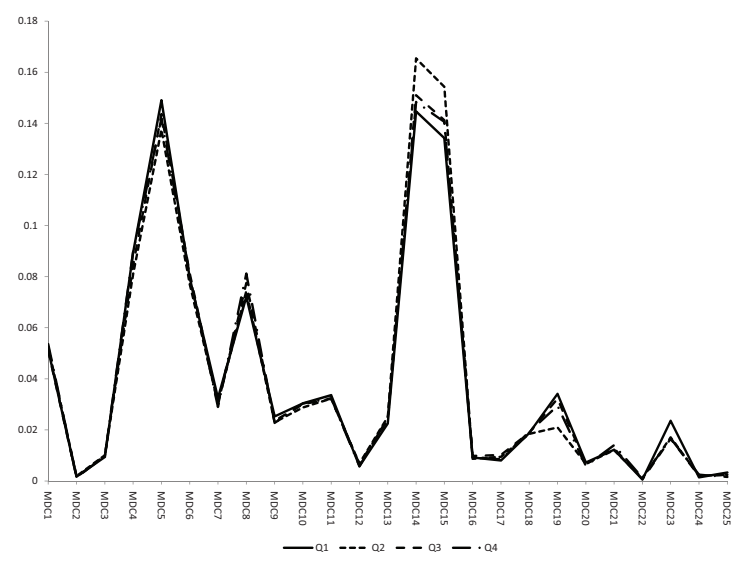

(b) Major Diagnostic Categories: All Patients

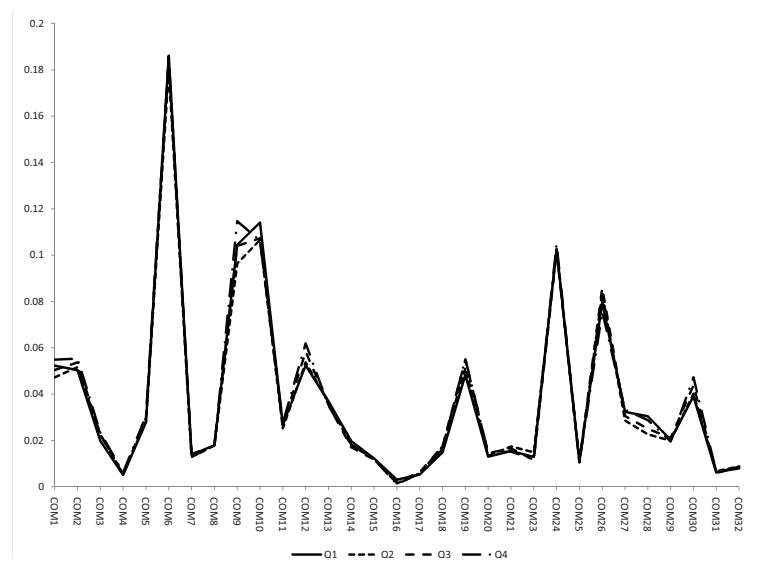

(c) Elixhauser Comorbidities: All Patients

Figure 1: Distribution of Clinical Variables 
Table 1: Descriptive Statistics

\begin{tabular}{|c|c|c|c|c|c|c|c|}
\hline & Q1 & Q2 & & Q3 & & Q4 & \\
\hline Avg. $\Delta$ in Market Uninsurance & -0.0052 & -0.0007 & $*$ & 0.0010 & $*$ & 0.0031 & * \\
\hline Avg. $\Delta$ in Insured AMI Mortality & -0.0023 & -0.0025 & & -0.0013 & $*$ & -0.0012 & $*$ \\
\hline Uninsurance Rate (10/20 miles) & 0.0733 & 0.0557 & $*$ & 0.0549 & $*$ & 0.0574 & * \\
\hline Insured AMI Mortality & 0.0823 & 0.0823 & & 0.0798 & $*$ & 0.0836 & * \\
\hline \multicolumn{8}{|l|}{ A. Insured AMI Patients } \\
\hline 18-34 years old & 0.0060 & 0.0056 & $*$ & 0.0050 & $*$ & 0.0055 & $*$ \\
\hline 35-64 years old & 0.3344 & 0.3414 & $*$ & 0.3349 & & 0.3513 & $*$ \\
\hline 65 years and above & 0.6596 & 0.6531 & $*$ & 0.6600 & & 0.6432 & * \\
\hline Female & 0.3748 & 0.3564 & $*$ & 0.3608 & $*$ & 0.3613 & * \\
\hline Non-Hispanic White & 0.5316 & 0.5404 & $*$ & 0.5773 & $*$ & 0.6620 & $*$ \\
\hline Non-Hispanic Black & 0.0597 & 0.0472 & $*$ & 0.0378 & $*$ & 0.0208 & * \\
\hline Hispanic & 0.0898 & 0.1217 & $*$ & 0.0796 & $*$ & 0.0581 & * \\
\hline \multicolumn{8}{|l|}{ B. All Patients } \\
\hline Less than 1 year & 0.1460 & 0.1665 & $*$ & 0.1527 & $*$ & 0.1529 & $*$ \\
\hline 1-17 years old & 0.0371 & 0.0367 & $*$ & 0.0363 & $*$ & 0.0418 & $*$ \\
\hline 18-34 years old & 0.1778 & 0.1892 & $*$ & 0.1816 & $*$ & 0.1815 & $*$ \\
\hline 35-64 years old & 0.3115 & 0.2925 & $*$ & 0.2997 & $*$ & 0.2970 & * \\
\hline 65 and above & 0.3276 & 0.3152 & $*$ & 0.3297 & $*$ & 0.3267 & $*$ \\
\hline Female & 0.5973 & 0.6096 & $*$ & 0.6052 & $*$ & 0.6055 & * \\
\hline Non-Hispanic White & 0.5187 & 0.5068 & $*$ & 0.5831 & $*$ & 0.6720 & $*$ \\
\hline Non-Hispanic Black & 0.1104 & 0.0722 & $*$ & 0.0804 & $*$ & 0.0423 & * \\
\hline Hispanic & 0.2808 & 0.3389 & $*$ & 0.2537 & $*$ & 0.2284 & $*$ \\
\hline \multicolumn{8}{|l|}{ C. Hospitals } \\
\hline Insured AMI Discharges & 136 & 190 & $*$ & 170 & $*$ & 176 & $*$ \\
\hline Total discharges & 9,036 & 12,527 & $*$ & 10,784 & $*$ & 10,261 & $*$ \\
\hline No. hospitals: $10 / 20$ miles & 8.6382 & 11.1677 & $*$ & 7.5304 & $*$ & 5.1969 & $*$ \\
\hline Urban & 0.8162 & 0.9397 & $*$ & 0.8415 & & 0.6738 & * \\
\hline For-profit & 0.2750 & 0.3088 & & 0.1867 & $*$ & 0.1692 & * \\
\hline Not-for-profit & 0.4485 & 0.5485 & $*$ & 0.6726 & $*$ & 0.6354 & * \\
\hline Public & 0.2765 & 0.1426 & $*$ & 0.1407 & $*$ & 0.1954 & * \\
\hline OBS & 680 & 680 & & 675 & & 650 & \\
\hline
\end{tabular}

Notes: The sample is split into quartiles using the average annual change in the 10/20-mile market uninsurance rate. Each cell represents the mean of the variable in that quartile. AMI mortality and the characteristics of insured AMI patients are weighted by insured AMI discharges, the characteristics of overall patients are weighted by total discharges and the uninsurance rates and hospital characteristics are unweighted. * significantly different from the bottom quartile at the $1 \%$ significance level. 
Table 2: Fixed Effects Estimation of the Effects of Uninsurance on the In-Hospital Mortality Rate of Insured AMI Patients

\begin{tabular}{|c|c|c|c|c|c|c|}
\hline \multirow[b]{2}{*}{ Uninsurance Rate } & $\begin{array}{l}\text { Hospital } \\
\text { (1) }\end{array}$ & $\begin{array}{l}\text { County } \\
(2)\end{array}$ & $\begin{array}{l}5 \text { miles } \\
(3)\end{array}$ & $\begin{array}{c}10 \text { miles } \\
(4)\end{array}$ & $\begin{array}{c}5 / 15 \text { miles } \\
(5)\end{array}$ & $\begin{array}{c}\text { 10/20 miles } \\
(6)\end{array}$ \\
\hline & $\begin{array}{c}0.060 \\
(0.069)\end{array}$ & $\begin{array}{c}0.058 \\
(0.020)\end{array}$ & $\begin{array}{c}0.059 \\
(0.055)\end{array}$ & $\begin{array}{c}0.061 \\
(0.045)\end{array}$ & $\begin{array}{c}0.059 \\
(0.053)\end{array}$ & $\begin{array}{c}0.060 \\
(0.042)\end{array}$ \\
\hline \multicolumn{7}{|c|}{ Excluding patient and hospital characteristics } \\
\hline UNINS & $\begin{array}{c}0.064^{* *} \\
(0.028)\end{array}$ & $\begin{array}{c}0.048 \\
(0.059)\end{array}$ & $\begin{array}{r}0.056^{*} \\
(0.032)\end{array}$ & $\begin{array}{c}0.069^{* *} \\
(0.031)\end{array}$ & $\begin{array}{c}0.054 \\
(0.032)\end{array}$ & $\begin{array}{c}0.072^{* *} \\
(0.031)\end{array}$ \\
\hline \multicolumn{7}{|c|}{ Including patient and hospital characteristics } \\
\hline UNINS & $\begin{array}{c}0.059^{* *} \\
(0.027)\end{array}$ & $\begin{array}{c}0.045 \\
(0.046)\end{array}$ & $\begin{array}{r}0.050^{*} \\
(0.028)\end{array}$ & $\begin{array}{c}0.066^{* *} \\
(0.026)\end{array}$ & $\begin{array}{r}0.048^{*} \\
(0.028)\end{array}$ & $\begin{array}{l}0.071^{* * *} \\
(0.026)\end{array}$ \\
\hline OBS & 2685 & 2685 & 2685 & 2685 & 2685 & 2685 \\
\hline
\end{tabular}

Notes: Each column represents the effect of uninsurance on the in-hospital mortality rate of insured AMI patients using a different market definition. Each regression includes demographic and clinical characteristics of insured heart attack patients in the hospital, demographic and clinical characteristics of all the patients in the hospital, basic hospital characteristics, hospital fixed effects and year effects (see section 4.3). Robust standard errors clustered at the county level are shown in parenthesis. The regressions are weighted by the number of insured AMI discharges at the hospital. $* p<0.10,{ }^{* *} p<0.05,{ }^{* * *} p<0.01$. 
Table 3: Threats to Internal Validity

\begin{tabular}{|c|c|c|c|c|c|c|}
\hline & $\begin{array}{l}\text { Hospital } \\
\text { (1) }\end{array}$ & $\begin{array}{l}\text { County } \\
(2)\end{array}$ & $\begin{array}{c}5 \text { miles } \\
(3)\end{array}$ & $\begin{array}{l}10 \text { miles } \\
(4)\end{array}$ & $\begin{array}{c}5 / 15 \text { miles } \\
(5)\end{array}$ & $\begin{array}{c}10 / 20 \text { miles } \\
(6)\end{array}$ \\
\hline \multicolumn{7}{|c|}{ A. Linear Fixed Effects Model } \\
\hline UNINS & $\begin{array}{c}0.059^{* *} \\
(0.027)\end{array}$ & $\begin{array}{c}0.045 \\
(0.046)\end{array}$ & $\begin{array}{c}0.050^{*} \\
(0.028)\end{array}$ & $\begin{array}{c}0.066^{* *} \\
(0.026)\end{array}$ & $\begin{array}{c}0.048^{*} \\
(0.028)\end{array}$ & $\begin{array}{l}0.071^{* * *} \\
(0.026)\end{array}$ \\
\hline \multicolumn{7}{|c|}{ B. Reverse Causality } \\
\hline $\begin{array}{l}\text { First Stag } \\
\text { PrUNINS }\end{array}$ & $\begin{array}{l}1.456^{* * *} \\
(0.079)\end{array}$ & $\begin{array}{l}1.067^{\text {*** }} \\
(0.011)\end{array}$ & $\begin{array}{l}1.289^{* * *} \\
(0.080)\end{array}$ & $\begin{array}{l}1.244^{* * *} \\
(0.106)\end{array}$ & $\begin{array}{l}1.287^{\text {*** }} \\
(0.079)\end{array}$ & $\begin{array}{l}1.241^{* * *} \\
(0.105)\end{array}$ \\
\hline F-statistic & {$[338.968]$} & {$[9180.532]$} & {$[260.467]$} & {$[138.667]$} & {$[268.534]$} & {$[140.907]$} \\
\hline $\begin{array}{l}\text { Fixed Effe } \\
\text { UNINS }\end{array}$ & $\begin{array}{c}\text { s Instrume } \\
0.043 \\
(0.033)\end{array}$ & $\begin{array}{c}\text { al Variable } \\
0.034 \\
(0.041)\end{array}$ & $\begin{array}{l}0.035 \\
\quad(0.034)\end{array}$ & $\begin{array}{c}0.048 \\
(0.031)\end{array}$ & $\begin{array}{c}0.035 \\
(0.034)\end{array}$ & $\begin{array}{c}0.054^{*} \\
(0.031)\end{array}$ \\
\hline $\begin{array}{l}\text { Hausman } \\
\text { P-value }\end{array}$ & $\begin{array}{l}1.021 \\
0.312\end{array}$ & $\begin{array}{l}2.316 \\
0.128\end{array}$ & $\begin{array}{l}0.773 \\
0.379\end{array}$ & $\begin{array}{l}2.256 \\
0.133\end{array}$ & $\begin{array}{l}0.643 \\
0.423\end{array}$ & $\begin{array}{l}1.887 \\
0.169\end{array}$ \\
\hline \multicolumn{7}{|c|}{ C. Patient Composition Effects } \\
\hline UNINS & $\begin{array}{c}0.019^{*} \\
(0.010)\end{array}$ & $\begin{array}{c}0.012 \\
(0.025)\end{array}$ & $\begin{array}{c}0.008 \\
(0.009)\end{array}$ & $\begin{array}{c}0.014 \\
(0.011)\end{array}$ & $\begin{array}{c}0.008 \\
(0.009)\end{array}$ & $\begin{array}{c}0.014 \\
(0.011)\end{array}$ \\
\hline \multicolumn{7}{|c|}{ D. Sample Selection Bias } \\
\hline $\begin{array}{l}\text { Hospital } \\
\text { UNINS }\end{array}$ & $\begin{array}{c}\text { s an Emerg } \\
0.156^{*} \\
(0.087)\end{array}$ & $\begin{array}{c}\text { Room } \\
0.188 \\
(0.233)\end{array}$ & $\begin{array}{c}0.118 \\
(0.103)\end{array}$ & $\begin{array}{c}0.136 \\
(0.106)\end{array}$ & $\begin{array}{c}0.109 \\
(0.104)\end{array}$ & $\begin{array}{c}0.108 \\
(0.109)\end{array}$ \\
\hline $\begin{array}{l}24 \text { Hour o } \\
\text { UNINS }\end{array}$ & $\begin{array}{c}\text { Premise En } \\
0.006 \\
(0.053)\end{array}$ & $\begin{array}{c}\text { ergency Serv } \\
0.002 \\
(0.127)\end{array}$ & $\begin{array}{c}0.056 \\
(0.082)\end{array}$ & $\begin{array}{r}-0.040 \\
(0.051)\end{array}$ & $\begin{array}{c}0.057 \\
(0.084)\end{array}$ & $\begin{array}{c}-0.030 \\
(0.055)\end{array}$ \\
\hline $\begin{array}{l}\text { Routine D } \\
\text { UNINS }\end{array}$ & $\begin{array}{c}\text { charge to } \mathbf{H} \\
-0.105 \\
(0.115)\end{array}$ & $\begin{array}{l}\text { me } \\
\quad-0.178^{* *} \\
\quad(0.088)\end{array}$ & $\begin{array}{c}-0.068 \\
(0.100)\end{array}$ & $\begin{array}{r}-0.007 \\
(0.070)\end{array}$ & $\begin{array}{r}-0.082 \\
(0.104)\end{array}$ & $\begin{array}{r}-0.007 \\
(0.071)\end{array}$ \\
\hline $\begin{array}{l}\text { Length of } \\
\text { UNINS }\end{array}$ & $\begin{array}{l}\text { tay } \\
\quad 0.254 \\
(0.708)\end{array}$ & $\begin{array}{c}1.202 \\
(0.944)\end{array}$ & $\begin{array}{l}1.334^{* *} \\
(0.607)\end{array}$ & $\begin{array}{l}1.352^{* *} \\
(0.638)\end{array}$ & $\begin{array}{r}1.196^{*} \\
(0.602)\end{array}$ & $\begin{array}{r}1.241^{*} \\
(0.628)\end{array}$ \\
\hline $\begin{array}{l}\text { Transfer } \mathbf{t} \\
\text { UNINS }\end{array}$ & $\begin{array}{c}\text { Another Hc } \\
0.033 \\
(0.094)\end{array}$ & $\begin{array}{l}\text { pital } \\
\qquad \begin{array}{l}0.001 \\
(0.086)\end{array}\end{array}$ & $\begin{array}{c}-0.034 \\
(0.081)\end{array}$ & $\begin{array}{c}-0.095 \\
(0.063)\end{array}$ & $\begin{array}{c}-0.017 \\
(0.087)\end{array}$ & $\begin{array}{r}-0.103^{*} \\
(0.060)\end{array}$ \\
\hline $\begin{array}{l}\text { Transfers } \\
\text { UNINS }\end{array}$ & $\begin{array}{c}\text { Another F } \\
0.024 \\
(0.099)\end{array}$ & $\begin{array}{l}\text { ility } \\
0.069 \\
(0.107)\end{array}$ & $\begin{array}{r}-0.037 \\
(0.088)\end{array}$ & $\begin{array}{c}-0.094 \\
(0.066)\end{array}$ & $\begin{array}{c}-0.019 \\
(0.093)\end{array}$ & $\begin{array}{c}-0.098 \\
(0.064)\end{array}$ \\
\hline
\end{tabular}


Table 3: Threats to Internal Validity (cont'd)

\begin{tabular}{lcccccc}
\hline & $\begin{array}{c}\text { Hospital } \\
(1)\end{array}$ & $\begin{array}{c}\text { County } \\
(2)\end{array}$ & $\begin{array}{c}5 \text { miles } \\
(3)\end{array}$ & $\begin{array}{c}10 \text { miles } \\
(4)\end{array}$ & $\begin{array}{c}5 / 15 \text { miles } \\
(5)\end{array}$ & $\begin{array}{c}10 / 20 \text { miles } \\
(6)\end{array}$ \\
\cline { 2 - 7 } E. Unobserved Trends & & & & \\
UNINS & $0.051^{* *}$ & 0.003 & 0.036 & $0.050^{* *}$ & 0.036 & $0.055^{* * *}$ \\
& $(0.024)$ & $(0.037)$ & $(0.025)$ & $(0.020)$ & $(0.026)$ & $(0.020)$ \\
\hline \multicolumn{7}{r}{ F. Selection on Observed and Unobserved Variables (Altonji et al., 2005) } \\
Estimated Bias & -0.003 & -0.016 & 0.017 & 0.013 & 0.02 & 0.01 \\
Coefficient of UNINS & 0.059 & 0.045 & 0.05 & 0.066 & 0.048 & 0.071 \\
Bias Factor & -18.22 & -2.77 & 2.88 & 5.00 & 2.45 & 6.99 \\
\hline OBS & 2685 & 2685 & 2685 & 2685 & 2685 & 2685 \\
\hline
\end{tabular}

Notes: Each column represents a different market definition. Panel A reproduces the effect of uninsurance on the in-hospital mortality rate of insured AMI patients using a linear fixed effects model. Panel B examines reverse causality using a fixed-effects instrumental variable approach. The first row reports the coefficient estimates on the predicted uninsurance rate from a regression of the actual uninsurance on the predicted one, i.e. the first-stage. The $\mathrm{F}$-statistic from a Wald test that the estimated coefficient is equal to 0 is provided in brackets. The second row provides the effect of uninsurance on the in-hospital mortality rate of insured AMI patients from a 2SLS model using the predicted uninsurance rate as the instrument. The Hausman statistic testing the equality of the linear FE estimate to the FE IV estimate and its associated p-value are provided below the 2SLS estimates. Each regression in each row includes a full set of controls (see section 4.3), hospital fixed effects and year effects. Panel $\mathrm{C}$ examines patient composition effects and provides results from a specification regressing the predicted insured AMI mortality at the hospital on the uninsurance rate, year and hospital fixed effects. The predicted insured AMI mortality is obtained from a first stage by regressing the insured AMI mortality at the hospital on observable characteristics described in section 4.3. For more detail, see section 5.2.2. Panel D examines a potential bias from sample selection by re-estimating the baseline specification with new outcome variables: availability of an ER room, provision of 24-hour ER services on premise, the fraction insured AMI patients who were routinely discharged to home, transferred to another hospital, transferred to another facility, and the average length of stay among insured AMI patients. Panel E investigates robustness to unobserved trends by regressing the insured AMI mortality at the hospital on the uninsurance rate, full set of control variables (see section 4.3), hospital fixed effects and year effects, as well as a county specific time trend. Panel F applies the framework developed by Altonji et al. (2005). See 5.2.5 for a description of the rows. All regressions are weighted by the number of insured AMI discharges at the hospital. Robust standard errors clustered at the county level are shown in parenthesis. ${ }^{*} p<0.10,{ }^{* *} p<0.05,{ }^{* * *} p<0.01$. 
Table 4: Additional Robustness Checks

\begin{tabular}{|c|c|c|c|c|c|c|}
\hline & $\begin{array}{l}\text { Hospital } \\
\quad(1)\end{array}$ & $\begin{array}{l}\text { County } \\
(2)\end{array}$ & $\begin{array}{l}5 \text { miles } \\
(3)\end{array}$ & $\begin{array}{l}10 \text { miles } \\
(4)\end{array}$ & $\begin{array}{c}5 / 15 \text { miles } \\
(5)\end{array}$ & $\begin{array}{c}10 / 20 \text { miles } \\
(6)\end{array}$ \\
\hline \multicolumn{7}{|c|}{ A. Linear Fixed Effects Model } \\
\hline UNINS & $\begin{array}{c}0.059^{* *} \\
(0.027)\end{array}$ & $\begin{array}{c}0.045 \\
(0.046)\end{array}$ & $\begin{array}{c}0.050^{*} \\
(0.028)\end{array}$ & $\begin{array}{c}0.066^{* *} \\
(0.026)\end{array}$ & $\begin{array}{r}0.048^{*} \\
(0.028)\end{array}$ & $\begin{array}{l}0.071^{* * *} \\
(0.026)\end{array}$ \\
\hline \multicolumn{7}{|c|}{ B. Alternative Measures of Uninsurance } \\
\hline Patient Zip Code & & $\begin{array}{c}0.040 \\
(0.048)\end{array}$ & $\begin{array}{c}0.048 \\
(0.048)\end{array}$ & $\begin{array}{c}0.045 \\
(0.050)\end{array}$ & $\begin{array}{c}0.050 \\
(0.052)\end{array}$ & $\begin{array}{c}0.051 \\
(0.053)\end{array}$ \\
\hline Cost & $\begin{array}{c}0.056^{*} \\
(0.030)\end{array}$ & $\begin{array}{c}0.024 \\
(0.033)\end{array}$ & $\begin{array}{c}0.040 \\
(0.029)\end{array}$ & $\begin{array}{l}0.067^{* * *} \\
(0.024)\end{array}$ & $\begin{array}{c}0.035 \\
(0.030)\end{array}$ & $\begin{array}{l}0.071^{* * *} \\
(0.024)\end{array}$ \\
\hline Length of Stay & $\begin{array}{c}0.051^{*} \\
(0.028)\end{array}$ & $\begin{array}{c}0.041 \\
(0.051)\end{array}$ & $\begin{array}{c}0.043 \\
(0.030)\end{array}$ & $\begin{array}{c}0.073^{* *} \\
(0.031)\end{array}$ & $\begin{array}{c}0.040 \\
(0.031)\end{array}$ & $\begin{array}{l}0.077^{* *} \\
(0.031)\end{array}$ \\
\hline Weighted Distance & & & $\begin{array}{c}0.052^{* *} \\
(0.025)\end{array}$ & $\begin{array}{l}0.060^{* *} \\
(0.027)\end{array}$ & $\begin{array}{c}0.052^{* *} \\
(0.026)\end{array}$ & $\begin{array}{l}0.061^{* *} \\
(0.027)\end{array}$ \\
\hline ER Admission & $\begin{array}{l}0.115^{* *} \\
(0.056)\end{array}$ & $\begin{array}{c}0.164 \\
(0.125)\end{array}$ & $\begin{array}{c}0.083 \\
(0.057)\end{array}$ & $\begin{array}{c}0.109^{* *} \\
(0.050)\end{array}$ & $\begin{array}{c}0.080 \\
(0.057)\end{array}$ & $\begin{array}{c}0.123^{* *} \\
(0.047)\end{array}$ \\
\hline Non-AMI & $\begin{array}{l}0.061^{* *} \\
(0.027)\end{array}$ & $\begin{array}{c}0.046 \\
(0.047)\end{array}$ & $\begin{array}{c}0.051^{*} \\
(0.029)\end{array}$ & $\begin{array}{c}0.067^{* *} \\
(0.027)\end{array}$ & $\begin{array}{r}0.049^{*} \\
(0.029)\end{array}$ & $\begin{array}{l}0.072^{* * *} \\
(0.027)\end{array}$ \\
\hline \multicolumn{7}{|c|}{ C. Analysis Sample } \\
\hline $\begin{array}{l}\text { 30+ Insured AN } \\
\text { UNINS }\end{array}$ & $\begin{array}{c}\text { [I Discharg } \\
0.057^{* *} \\
(0.023)\end{array}$ & $\begin{array}{c}0.041 \\
(0.044)\end{array}$ & $\begin{array}{l}0.056^{* *} \\
(0.026)\end{array}$ & $\begin{array}{l}0.069^{* * *} \\
(0.022)\end{array}$ & $\begin{array}{r}0.053^{*} \\
(0.027)\end{array}$ & $\begin{array}{l}0.074^{* * *} \\
(0.022)\end{array}$ \\
\hline $\begin{array}{l}\text { 150+ Insured A } \\
\text { UNINS }\end{array}$ & $\begin{array}{c}\text { MI Dischar } \\
0.086^{* *} \\
(0.033)\end{array}$ & $\begin{array}{l}\text { es } \\
\quad 0.130^{* * *} \\
(0.034)\end{array}$ & $\begin{array}{c}0.068 \\
(0.069)\end{array}$ & $\begin{array}{l}0.175^{* * *} \\
(0.052)\end{array}$ & $\begin{array}{c}0.054 \\
(0.063)\end{array}$ & $\begin{array}{l}0.163^{* * *} \\
(0.049)\end{array}$ \\
\hline $\begin{array}{l}\text { Balanced Panel } \\
\text { UNINS }\end{array}$ & $\begin{array}{c}0.053^{* *} \\
(0.025)\end{array}$ & $\begin{array}{c}0.042 \\
(0.045)\end{array}$ & $\begin{array}{c}0.047 \\
(0.029)\end{array}$ & $\begin{array}{c}0.063^{* *} \\
(0.026)\end{array}$ & $\begin{array}{c}0.046 \\
(0.029)\end{array}$ & $\begin{array}{c}0.069^{* *} \\
(0.026)\end{array}$ \\
\hline
\end{tabular}


Table 4: Additional Robustness Checks (cont'd)

\begin{tabular}{|c|c|c|c|c|c|c|}
\hline & $\begin{array}{l}\text { Hospital } \\
\text { (1) }\end{array}$ & $\begin{array}{c}\text { County } \\
(2)\end{array}$ & $\begin{array}{l}5 \text { miles } \\
(3)\end{array}$ & $\begin{array}{c}10 \text { miles } \\
(4)\end{array}$ & $\begin{array}{c}5 / 15 \text { miles } \\
(5)\end{array}$ & $\begin{array}{c}10 / 20 \text { miles } \\
(6)\end{array}$ \\
\hline \multicolumn{7}{|c|}{ D. Other Emergency Outcomes } \\
\hline \multicolumn{7}{|c|}{ Insured Stroke Mortality } \\
\hline UNINS & $\begin{array}{c}0.031 \\
(0.041)\end{array}$ & $\begin{array}{c}0.023 \\
(0.063)\end{array}$ & $\begin{array}{c}0.096^{* *} \\
(0.047)\end{array}$ & $\begin{array}{l}0.132^{* *} \\
(0.053)\end{array}$ & $\begin{array}{l}0.100^{* *} \\
(0.046)\end{array}$ & $\begin{array}{l}0.136^{* *} \\
(0.053)\end{array}$ \\
\hline \multicolumn{7}{|c|}{ Insured Hip Fracture Mortality } \\
\hline UNINS & $\begin{array}{c}0.040 \\
(0.030)\end{array}$ & $\begin{array}{l}0.073^{* * *} \\
(0.026)\end{array}$ & $\begin{array}{c}0.004 \\
(0.037)\end{array}$ & $\begin{array}{c}0.008 \\
(0.038)\end{array}$ & $\begin{array}{c}0.002 \\
(0.037)\end{array}$ & $\begin{array}{c}0.007 \\
(0.038)\end{array}$ \\
\hline \multicolumn{7}{|c|}{ E. Model Selection } \\
\hline \multicolumn{7}{|c|}{ Fixed Effects Fractional Logit Model } \\
\hline UNINS & $\begin{array}{c}0.051^{* *} \\
(0.023)\end{array}$ & $\begin{array}{c}0.048 \\
(0.040)\end{array}$ & $\begin{array}{c}0.044^{*} \\
(0.026)\end{array}$ & $\begin{array}{c}0.060^{* *} \\
(0.023)\end{array}$ & $\begin{array}{c}0.041 \\
(0.026)\end{array}$ & $\begin{array}{l}0.064^{* * *} \\
(0.023)\end{array}$ \\
\hline \multicolumn{7}{|c|}{ Long Difference Model } \\
\hline UNINS & $\begin{array}{c}0.069^{*} \\
(0.035)\end{array}$ & $\begin{array}{c}0.162 \\
(0.130)\end{array}$ & $\begin{array}{c}0.119^{* *} \\
(0.046)\end{array}$ & $\begin{array}{l}0.140^{* * *} \\
(0.045)\end{array}$ & $\begin{array}{l}0.118^{* * *} \\
(0.044)\end{array}$ & $\begin{array}{l}0.159^{* * *} \\
(0.043)\end{array}$ \\
\hline \multicolumn{7}{|c|}{ Lagged Dependent Variable Model } \\
\hline UNINS & $\begin{array}{c}0.031^{* *} \\
(0.015)\end{array}$ & $\begin{array}{c}0.067^{* *} \\
(0.029)\end{array}$ & $\begin{array}{c}0.023 \\
(0.015)\end{array}$ & $\begin{array}{c}0.029 \\
(0.018)\end{array}$ & $\begin{array}{c}0.019 \\
(0.016)\end{array}$ & $\begin{array}{c}0.025 \\
(0.017)\end{array}$ \\
\hline
\end{tabular}

Notes: Each column represents a different market definition. Panel A reproduces the effect of uninsurance on the in-hospital mortality rate of insured AMI patients using a linear fixed effects model. Panel B examines robustness to alternative measures of uninsurance. Panel C checks the sensitivity of the results to the selection of the analysis sample. Panel D provides results for other emergency outcomes that are common among the elderly. Panel E investigates robustness to model specification. For more detail, see section 5.2.6. Each regression in each panel includes a full set of controls (see section 4.3), hospital fixed effects and year effects. The number of observations vary across rows. The regressions are weighted by the number of insured AMI discharges at the hospital except in the long difference model (row 2, Panel E) where the regressions are weighted by the average number of insured AMI discharges at the hospital in 1999 and 2006. Robust standard errors clustered at the county level are shown in parenthesis. ${ }^{*} p<0.10,{ }^{* *} p<0.05,{ }^{* * *} p<0.01$. 


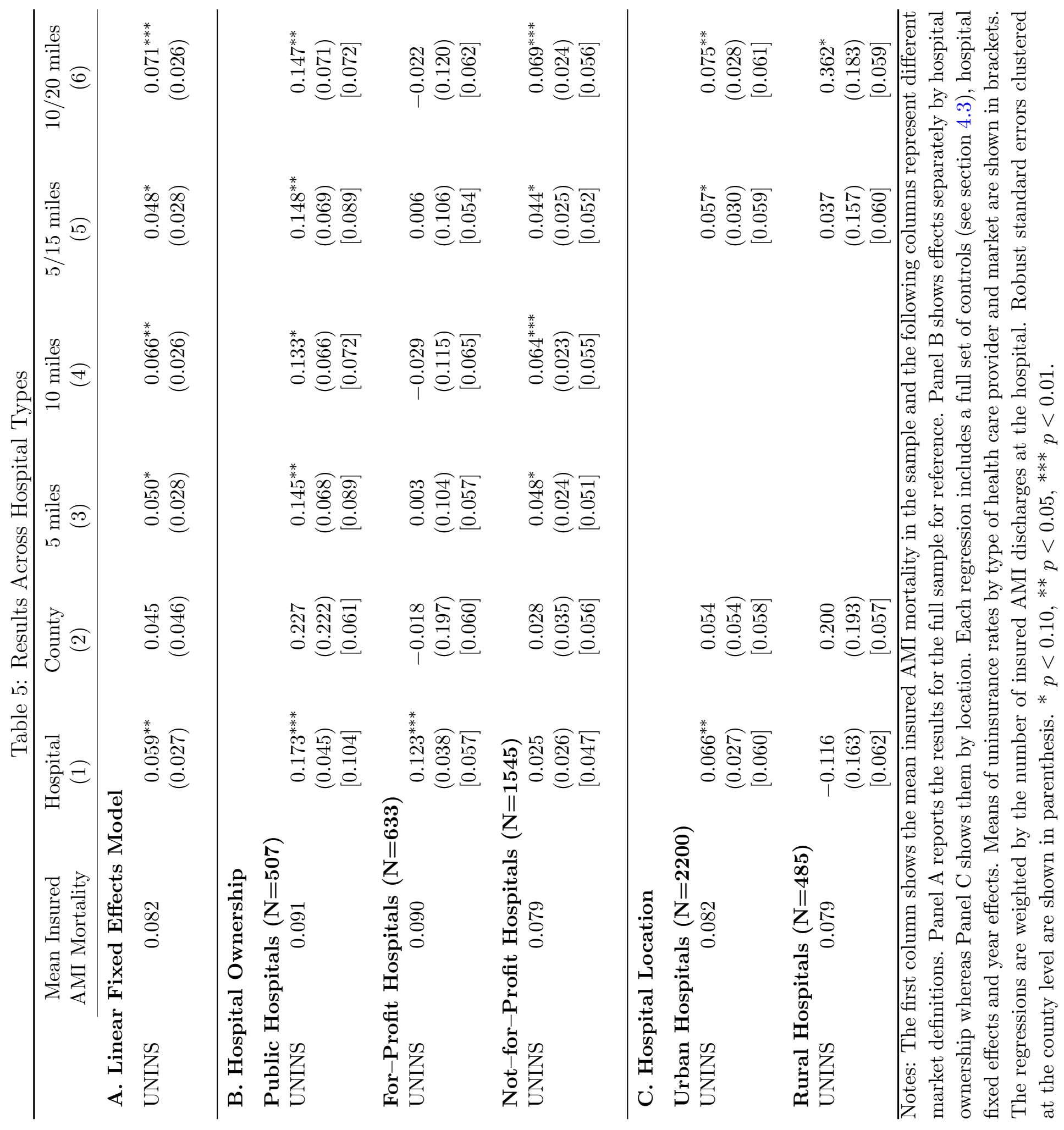




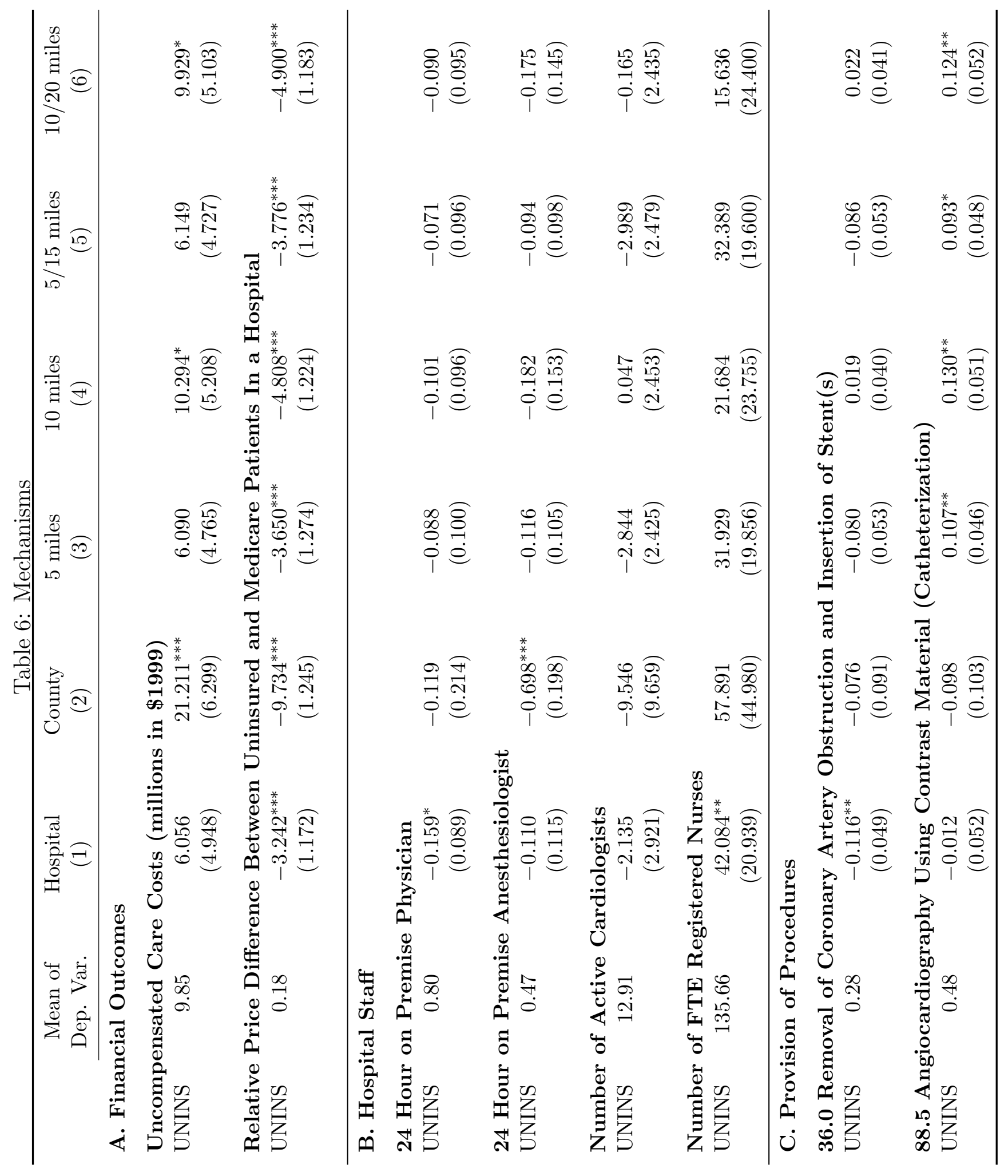




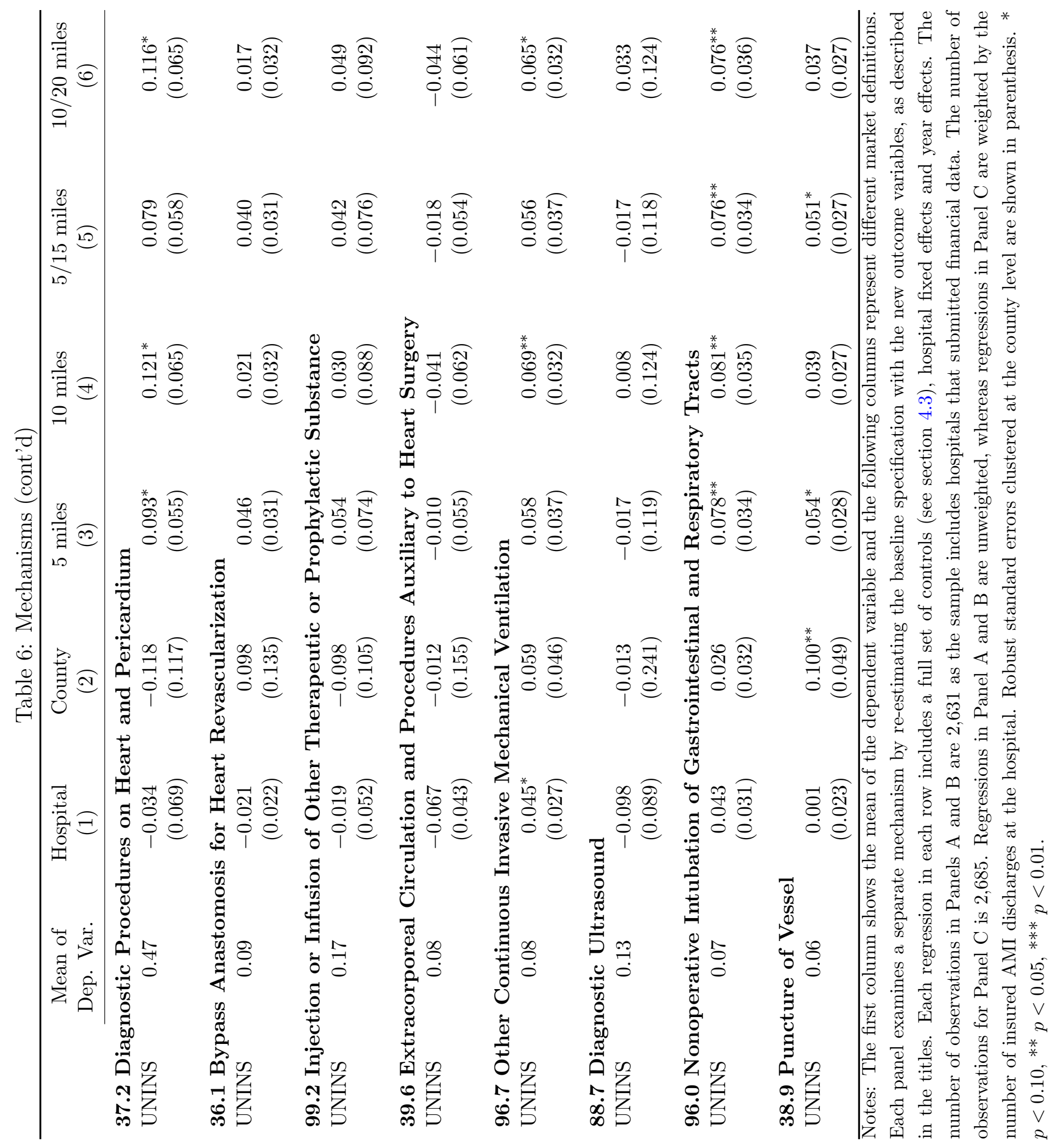




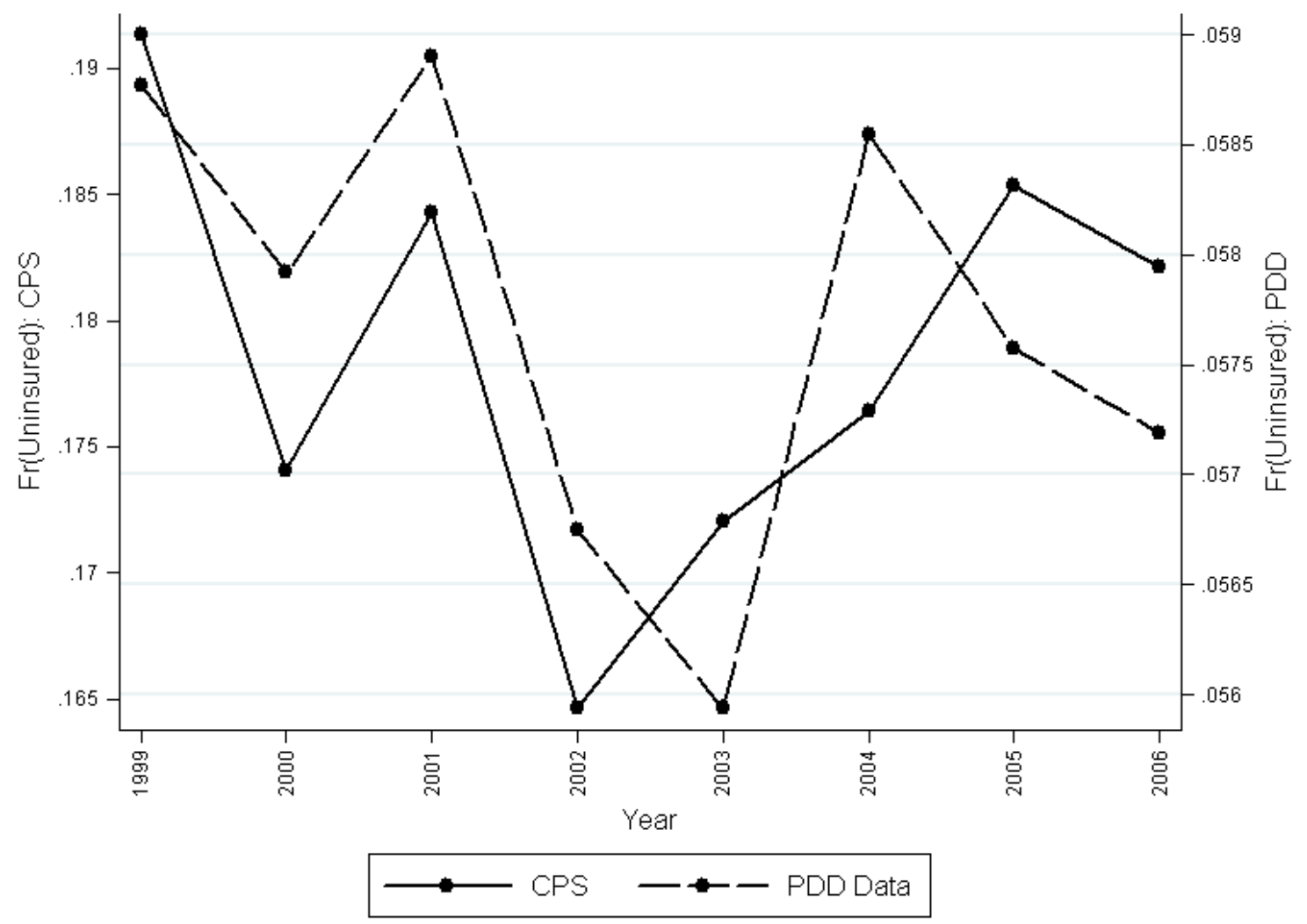

Figure A1: Variation in Uninsurance in California - CPS versus Patient Discharge Data 
Table A1: Elixhauser Comorbidities

\begin{tabular}{ll}
\hline Comorbidity & \multicolumn{1}{c}{ Explanation } \\
\hline Comorbidity 1 & Congestive heart failure \\
Comorbidity 2 & Cardiac arrhythmias \\
Comorbidity 3 & Valvular disease \\
Comorbidity 4 & Pulmonary circulation disorders \\
Comorbidity 5 & Peripheral vascular disorders \\
Comorbidity 6 & Hypertension \\
Comorbidity 7 & Paralysis \\
Comorbidity 8 & Other neurological disorders \\
Comorbidity 9 & Chronic pulmonary disease \\
Comorbidity 10 & Diabetes, uncomplicated \\
Comorbidity 11 & Diabetes, complicated \\
Comorbidity 12 & Hypothyroidism \\
Comorbidity 13 & Renal failure \\
Comorbidity 14 & Liver disease \\
Comorbidity 15 & Peptic ulcer disease \\
Comorbidity 16 & AIDS \\
Comorbidity 17 & Lymphoma \\
Comorbidity 18 & Metastatic cancer \\
Comorbidity 19 & Solid tumor \\
Comorbidity 20 & Rheumatoid arthritis/collagen vascular diseases \\
Comorbidity 21 & Coagulopathy \\
Comorbidity 22 & Obesity \\
Comorbidity 23 & Weight loss \\
Comorbidity 24 & Fluid and electrolyte disorders \\
Comorbidity 25 & Blood loss anemia \\
Comorbidity 26 & Deficiency anemias \\
Comorbidity 27 & Alcohol abuse \\
Comorbidity 28 & Drug abuse \\
Comorbidity 29 & Psychoses \\
Comorbidity 30 & Depression \\
Complication & Adverse events from treatments or procedures \\
Surgical DRG & Surgery performed in the hospital \\
\hline
\end{tabular}

